\title{
OS OBJETOS EDUCACIONAIS DIGITAIS EM LINGUAGEM E INTERAÇÃO: AVANÇOS, PERMANÊNCIAS OU RETROCESSOS?
}

\section{DIGITAL EDUCATIONAL OBJECTS IN 'LINGUAGEM E INTERAÇÃO’: ADVANCES, STAYS OR SETBACKS?}

\author{
Luciana Pereira Silva \\ Universidade Tecnológica Federal do Paraná \\ silvapereiralu@gmail.com \\ Andreia Rutiquewiski \\ Universidade Tecnológica Federal do Paraná \\ andreiaruti@gmail.com \\ Juliana Benatti \\ Universidade Tecnológica Federal do Paraná \\ julianabenatti@alunos.utfpr.edu.br
}

RESUMO: Este artigo analisa os Objetos Educacionais Digitais que acompanham a coleção didática Linguagem e Interação, indicada ao ensino médio 2018-2020 via Plano Nacional do Livro Didático. Segundo a literatura, esse material digital pode subsidiar as aulas de língua materna a partir da pedagogia dos multiletramentos em substituição a práticas de ensino tradicionais. Para tanto, foram realizadas pesquisas de caráter documental (documentos oficiais de ensino) e bibliográfico (LEFFA, 2006; ANTUNES, 2007; MARCUSCHI, 2008; DIONÍSIO 2011, 2014; ROJO, 2012, 2013, 2017, entre outros). Em seguida, foram analisados os Objetos Educacionais, cotejando-os à fundamentação teórica. Propõe-se, para a caracterização do corpus, dois momentos de análise: 1) a partir das propriedades estabelecidas por Leffa (granularidade, reusabilidade, interoperabilidade e recuperabilidade); e 2) a partir dos fundamentos teórico-metodológicos do ensino de Português como língua materna. Os resultados confirmam que, apesar desse material digital enquadrar-se na definição prototípica, deixa a desejar quanto ao desenvolvimento das habilidades linguísticas dos estudantes com vistas aos multiletramentos.

PALAVRAS-CHAVE: ensino-aprendizagem de língua materna; tecnologias digitais de informação e comunicação; objetos educacionais digitais; multiletramentos.

\begin{abstract}
This article analyses the Digital Educational Objects which follow the didactic collection Linguagem e Interação, appointed to be used in the middle school 2018-2000 via Plano Nacional do Livro Didático. Based on the current literature, this digital material may help in the mother tongue classes anchored in a multiliteracy pedagogy, replacing traditional practices. In doing so, a research was conducted based on teaching official documents as well as a bibliographic research (LEFFA, 2006; ANTUNES, 2007; MARCUSCHI, 2008; DIONÍSIO, 2011, 2014; ROJO, 2012, 2013, 2017, among others. Then, the Digital Educational Objects were analyzed taking into consideration the chosen theory. It proposes, for the characterization of the corpus, two moments of analysis: 1) from the properties established by Leffa (granularity, reusability, interoperability and
\end{abstract}


recoverability); and 2) from the theoretical-methodological foundations of the teaching of Portuguese as a mother tongue. The results confirm that although this digital material fits in with the prototypical definition, it leaves no room for the development of students' language skills, considering the multiliteracies.

KEYWORDS: teaching-learning of mother tongue; digital information and communication technologies; digital educational objects; multiliteracies.

\section{Considerações iniciais}

No cenário de ensino no Brasil, algumas mudanças vêm acontecendo devido às transformações ocorridas na sociedade desde que as Tecnologias Digitais de Informação e Comunicação (doravante TDIC) começaram a ser compreendidas como auxiliares do processo de ensino-aprendizagem. Diante disso, instituições acadêmicas, editoras de livros didáticos e educadores têm investido tanto em pesquisas quanto em produções de objetos digitais visando promover aprendizagens subsidiadas por aparatos tecnológicos.

Assim, para que a escola acompanhe as mudanças sociais que a cercam, promovendo e desenvolvendo a interação por meio das diversas práticas sociais da linguagem, sugere-se a necessidade de trabalhar a partir da perspectiva do multiletramento, que compreende uma noção muito importante hoje: a pluriculturalidade e a multimodalidade ${ }^{1}$. De acordo com Dionísio (2014), os estudos nesse campo têm se desenvolvido nas últimas décadas a fim de tratar temas discutidos em sociedade, como em relação às novas mídias e tecnologias. Nessa perspectiva, entende-se por conteúdo multimídia os chamados Objetos Educacionais Digitais (doravante OED) que, segundo o edital do Programa Nacional do Livro Didático (PNLD) de 2014, podem ser apresentados "nas categorias: audiovisual, jogo eletrônico educativo, simulador e infográfico animado" (BRASIL, 2011, p. 2).

Dessa forma, o presente trabalho pretende analisar os OED contemplados pela coleção didática de Língua Portuguesa Linguagem e Interação da editora Ática, observando como esses materiais desenvolvem o ensino de Português como língua materna. Essa coleção didática foi aprovada pelo Ministério da Educação (MEC) durante o processo de avaliação de livros didáticos para o interstício 2018-2020. Sendo assim, os OED analisados neste trabalho, consequentemente, também começarão a ser utilizados a partir de 2018, fato que torna a pesquisa atual e, principalmente, justifica a sua relevância.

Para a exposição desse estudo, esta pesquisa organiza-se da seguinte forma: inicialmente, a fundamentação teórica apresenta alguns pressupostos acerca do impacto da tecnologia no ensino de Língua Portuguesa. Na sequência, realizam-se, efetivamente, as análises dos objetos. Num primeiro momento, a análise pauta-se nos critérios caracterizadores de OED de Leffa (2006). Em seguida, a análise centra-se nos fundamentos teórico-metodológicos do ensino de língua materna e, por fim, apresenta-se a discussão dos resultados obtidos, por meio dos quais foram produzidas categorias de análise dos OED em foco e cujos resultados permitiram a reflexão proposta nas considerações que encerram este trabalho.

\section{Esse aspecto será aprofundado durante o trabalho.}




\section{0 ensino de Língua Materna na atualidade: impactos da tecnologia digital}

A sociedade atual vive imersa em um mundo tecnológico no qual dispositivos digitais estão frequentemente presentes. Nesse contexto, a tecnologia, além de impulsionar a produção e a disseminação da informação, é responsável pela mediação de grande parte das ações concretizadas no cotidiano da sociedade. Assim, com essa nova configuração social, a tecnologia é um agente de mudanças e as inovações tecnológicas podem resultar em grandes transformações (WILEY, 2002).

Lalueza, Crespo e Camps (2010, p. 51) afirmam que "ao mudarmos as ferramentas culturais com as quais lidamos, também alteram-se as formas de inteligência que a sociedade valoriza. Ou seja, há alterações, inclusive, no desenvolvimento cognitivo, social e emocional dos indivíduos". Essa afirmação é extremamente relevante e nos faz pensar, sobretudo, no papel da escola na contemporaneidade, que precisa contemplar e atender às demandas e às expectativas dos jovens estudantes, indivíduos nascidos e criados em constante contato com as tecnologias digitais.

Compreende-se, desse modo, que é necessário, neste momento histórico-social, alterar a base do ensino de língua materna, oferecendo aos estudantes propostas de trabalho que extrapolem o texto escrito, eleito até então o principal objeto de estudo. Rojo (2017, p. 4), acerca desse fato, defende que "não basta enfatizar os letramentos da letra ou do impresso e os gêneros discursivos da tradição e do cânone. É urgente enfocar os multiletramentos que circulam na vida contemporânea de nossos alunos".

Para a autora, o conceito de multiletramentos sugere dois relevantes tipos de multiplicidade presentes na sociedade atual: a cultural das populações e a semiótica de constituições dos textos por meio dos quais ela se informa e se comunica (ROJO, 2012, p. 13).

Assim, em um contexto de multiplicidade de linguagens, mídias e tecnologias, são requeridas novas práticas de leitura, escrita e análise crítica, portanto, são necessários multiletramentos:

\footnotetext{
Multiletramentos são as práticas de trato com os textos multimodais ou multissemióticos contemporâneos - majoritariamente digitais, mas também impressos -, que incluem procedimentos (como gestos para ler, por exemplo) e capacidades de leitura e produção que vão muito além da compreensão e produção de textos escritos, pois incorporam a leitura e (re)produção de imagens e fotos, diagramas, gráficos e infográficos, vídeos, áudio etc. (ROJO, 2017, p. 4).
}

Observa-se, na citação acima, que sendo a multimodalidade uma característica majoritariamente digital não seria apropriado desconsiderar esse aspecto nas práticas desenvolvidas com os OED. Propõe-se pensar na multimodalidade como um ponto definidor do multiletramento, já que esse visa compreender os múltiplos modos dos textos em circulação atualmente, incorporando, de acordo com Rojo, linguagem escrita e linguagem audiovisual (fotos, diagramas, gráficos, vídeos, imagem estática e em movimento). Percebe-se que a forte presença das TDIC movimenta a maneira de entender a produção e a leitura de textos, por isso, a multimodalidade, a qual está sendo proporcionada por esses gêneros, aponta-nos para uma necessidade de abranger os multiletramentos na contemporaneidade. 
Coscarelli (2009) já se mostrava de acordo com essa perspectiva ao argumentar que, devido às práticas cada vez mais cotidianas do não verbal, o leitor precisa saber lidar com as diversas habilidades que envolvem a multimodalidade. A autora ressalta ainda que as práticas verbais não devem ser esquecidas por completo, mas a elas devem ser acrescidas outras linguagens de leitura e produção de textos. Acerca disso, a autora expõe que:

\footnotetext{
Se antes os textos contavam quase que exclusivamente com a linguagem verbal, agora eles contam também com outras linguagens que podem e devem ser incorporadas a eles. Sendo assim, o aprendiz precisa saber lidar com a multimodalidade tanto como leitor quanto como autor. Isso não significa que ele não precise saber lidar com o verbal. Pelo contrário, para ser um bom leitor e produtor de textos multimodais - isto é, textos que lidam com diversas linguagens -, o sujeito precisa dominar uma série de habilidades de leitura e produção de textos verbais (COSCARELLI, 2009, p. 552).
}

Dessa maneira, Coscarelli explica que com os novos gêneros textuais advindos, em muitos casos, da cultura impressa, como o e-mail, o blog e também das novas formas de comunicação como as mensagens de celular, é preciso ampliar as habilidades do leitor incorporando o meio digital que se apresenta disponível aos usuários, não substituindo as competências que ele precisa ter para compreender o texto impresso. Assim, a multimodalidade passa a ser uma característica a qual o aprendiz necessita apreender visando a essa multiplicidade de linguagens que, segundo a autora, mostra-se presente desde o cinema, as revistas, os jornais, até a contemporaneidade em que se convive com a facilidade de encontrar textos multimodais que - além do material impresso - estão também disponibilizados e são propagados pelas TDIC.

Logo, diante de uma contemporaneidade na qual se têm novas práticas de letramento, cabe à escola conectar-se a essa nova ordem mundial e repensar suas práticas. Segundo Rojo, é "preciso que a instituição escolar prepare a população para um funcionamento da sociedade cada vez mais digital e também para buscar no ciberespaço um lugar para se encontrar, de maneira crítica, com diferenças e identidades múltiplas." (ROJO, 2013, p. 7). Para tanto, deve-se inserir as TDIC nas práticas pedagógicas nas escolas. Isso porque, segundo Rojo, a escola deve levar em conta os multiletramentos, as práticas, os procedimentos e os gêneros em circulação nos ambientes da cultura de massa e digital no mundo atual.

Diante disso, torna-se necessário compreender que a implementação do material digital nas escolas não deve ser o foco se pensado como um artefato de marketing, o qual se faz presente devido à sedução que causa ao observar uma coleção didática que o contenha, mas, primordialmente, deve-se refletir sobre essa nova cultura digital com a qual os alunos têm contato diário. É também nesse sentido que é fundamental pensarmos no conceito de multiletramento para demonstrar como um OED pode se aproximar da cultura digital promovendo uma aprendizagem interativa e significativa para os estudantes já totalmente imersos nessa cultura. 


\title{
2.1 Os objetos educacionais digitais
}

Para Coll, Mauri e Onrubia (2010), as TDIC são grandes aliadas para o processo de ensino e aprendizagem, pois são capazes de mediar as relações entre docentes, discentes e conteúdos. Essa mediação pode acontecer de diferentes modos, ou seja, pela elaboração de novos materiais de ensino, pela construção de roteiros de trabalho em sala de aula, pela exploração dos recursos próprios do meio virtual, entre outros.

Assim, os OED aparecem como uma das formas de desenvolver o ensino a partir do uso das tecnologias digitais em conjunto com materiais impressos, tanto que alguns livros didáticos distribuídos e recomendados pelo governo brasileiro (PNLD) trazem esse objeto, como uma alternativa inovadora, moderna e, portanto, de acordo com as recomendações da literatura.

Leffa é a principal referência quando se trata de OED. Em seu trabalho de 2006, encontram-se as primeiras definições e reflexões sobre o tema. Partindo de McGreal (2004), que faz uso de uma escala de definições hierárquicas buscando apresentar os objetos desde uma forma mais geral até a mais específica, Leffa (2006, p. 19) expõe quatro estágios dessa escala:

\author{
Qualquer coisa (DOWNES, 2003; FRIESEN, 2001; MORTIMER, 2002). \\ Qualquer coisa digital (WILEY, 2000). \\ Qualquer coisa com objetivo educacional (QUINN \& HOBBS, 2000). \\ Qualquer coisa digital com objetivo educacional (ALBERTA LEARNING, 2002; \\ CISCO SYSTEMS, 2001; KOPER, 2001).
}

Após percorrer um trajeto de compreensão, o autor é sucinto ao afirmar que o conceito dominante de um objeto de aprendizagem (OA) é qualquer coisa digital com objetivo educacional. Isto é, pode ser qualquer arquivo digital (texto, imagem ou vídeo), desde que usado para facilitar e promover a aprendizagem (LEFFA, 2006, p. 20).

Leffa (2006) estabeleceu também as quatro características principais que um OED deve possuir e, para isso, o autor se baseou, não somente na definição acima, mas também em uma definição oferecida pelo Programa de Extensão da Universidade de Wisconsin (WiscOnline):

\footnotetext{
Veja-se, por exemplo, a definição oferecida pelo Programa de Extensão da Universidade de Wisconsin (Wisconline): Pequena unidade eletrônica de informação educacional que se caracteriza por ser flexível, reusável, customizável, interoperável, recuperável, capaz de facilitar a aprendizagem baseada nas competências e aumentar o valor do conteúdo (University of Wisconsin-Extension). (LEFFA, 2006, p. 21).
}

Os termos reusável, customizável, interoperável, recuperável remetem respectivamente aos conceitos de granularidade, reusabilidade, interoperabilidade e recuperabilidade, as propriedades fundamentais que um objeto deve apresentar ${ }^{2}$.

2 Portanto, assume-se neste trabalho uma perspectiva de objeto de aprendizagem essencialmente digital. Entende-se que essa não é a única maneira de compreender a amplitude de um $\mathrm{OA}$, mas é aquela que, de acordo com Leffa (2006), no momento, mostra-se mais produtiva e com mais retorno para o ensino de línguas, tanto a materna como a estrangeira. uma vez que um objeto digital, por estar disponível na 
A granularidade, segundo Leffa (2006), diz respeito à capacidade dos objetos educacionais se encaixarem um ao outro formando blocos ou unidades de acordo com a necessidade do indivíduo interessado. Sendo assim, o OA é, portanto, um módulo que pode se ajustar a outros de várias maneiras, formando um conjunto homogêneo e funcional.

A ideia de reusabilidade, segunda característica, refere-se a uma economia de tempo de construção do objeto. Tendo em vista que os professores são os principais criadores dos objetos, é de fácil compreensão que eles queiram reaproveitar os objetos que construíram, reconstruindo, recriando e reinventando elementos dando um aspecto diferente ao OA. Ainda de acordo com o autor, ao utilizar um objeto, pode-se buscar meios de fazê-lo cada vez mais eficientemente:

O fato de o objeto ser usado não deveria esgotá-lo, mas, pelo contrário, torná-lo mais aprimorado e mais eficiente na aprendizagem, com um custo de tempo cada vez menor. O meio digital, pela sua rápida evolução, exige esse aprimoramento constante (LEFFA, 2006, p. 10).

Dessa maneira, é possível entender que para reusar um objeto é necessário que o OA evolua de maneira que se molde para se adequar às constantes transformações do meio digital. Assim, chegamos à terceira característica: a interoperabilidade. Leffa (2006) utiliza a metáfora de um camaleão para se fazer claro:

\footnotetext{
Usando uma metáfora, o correspondente mais próximo no mundo natural seria o camaleão, com a ressalva de que enquanto o camaleão muda apenas a cor externa, permanecendo com a mesma estrutura interna, o OA mantém a mesma aparência externa de um ambiente digital para outro, mas mudando sua estrutura interna (LEFFA, 2006, p. 12).
}

Para que o objeto se aproprie dessa característica, é necessário que ele seja compatível com diferentes sistemas operacionais, tipos de máquina ou navegadores. Ainda que essa deva ser uma preocupação ao produzir um OA, essa é uma tarefa do sistema de autoria e não do professor.

Por fim, a quarta e última característica é nomeada recuperabilidade e diz respeito à maneira como o objeto de aprendizagem será acessado pelo interessado, o que deve ocorrer de maneira fácil e rápida. Para isso, Leffa (2006) expõe que basta utilizar um sistema de catalogação no qual o indivíduo consiga encontrar o OA de que necessita por meio do título, da língua usada, de uma breve descrição, entre outros elementos que podem auxiliar o interessado a realizar sua escolha.

\section{Análise dos objetos educacionais digitais na obra Linguagem e Interação a partir das propriedades de LEFFA (2006)}

Como apresentado na fundamentação teórica, Leffa (2006) afirma que para que um material possa se caracterizar como um objeto educacional digital é necessário que ele Internet, apresenta um nível de alcance maior em vista de um objeto impresso em papel. 
apresente as seguintes propriedades: a granularidade, a reusabilidade, a interoperabilidade e a recuperabilidade.

A primeira característica, a granularidade, entende os objetos educacionais como peças que se encaixam e, assim, formam blocos maiores ou menores. Segundo Leffa, os OED são unidades que podem se combinar a outras unidades, resultando em um conjunto homogêneo e funcional. Além disso, o autor ressalta, que de acordo com o Centro de Recursos Online da Universidade de Wisconsin (Wisconsin Online Resource Center), um objeto educacional deve durar entre dois e quinze minutos - no entanto, a performance dos alunos pode tornar esse número maleável - e quanto menor o OED maior é a granularidade, ou seja, maior é a possibilidade de torná-lo parte de um bloco funcional de OED. Tendo em vista que os objetos analisados neste artigo se enquadram nas especificações anteriores é possível afirmar que essa é uma característica da qual eles se apropriam e, consequentemente, podem continuar a serem entendidos como um objeto educacional digital.

A reusabilidade, segunda característica, refere-se ao fato de reutilizar um objeto educacional pensando, não somente em uma economia financeira, mas principalmente em uma economia de tempo. O fato de reutilizar um objeto o faz ainda mais eficiente, já que, segundo Leffa (2006), ao usar mais de uma vez um mesmo objeto ele pode ser repensado, aprimorado e até unido a outros objetos educacionais. Dessa maneira, um OED pode ser reduplicado por meio de uma clonagem na qual um grande número de usuários pode ter acesso a ele simultaneamente e, também, pode evoluir no que diz respeito à capacidade de renovação a qual atribui ao objeto modificações que buscam constantemente aprimoramento. Em relação a esses aspectos, podemos apontar que os OED analisados também se mostram positivos, visto que têm a possibilidade de serem reaproveitados mediante considerações e sugestões dos usuários, por exemplo; e podem ser acessados por vários usuários ao mesmo tempo. Ainda que seja possível observar essa característica, vale ressaltar que os objetos são disponibilizados pela editora da coleção e por esse motivo tanto a reduplicação quanto a renovação se tornariam possíveis apenas por uma iniciativa da editora ${ }^{3}$.

Esse caráter de evolução pertencente aos OED nos conduz à terceira característica de Leffa (2006), a qual é intitulada interoperabilidade e compreende a capacidade de adaptação de um objeto educacional. De acordo com essa característica, o objeto educacional deve ser capaz de ser reproduzido da mesma maneira, independentemente de estar sendo rodado no Windows ou no Linux, no Internet Explorer ou no Firefox, num PC ou num Macintosh. Sendo assim, após acessar o site da editora e entrar em contato com os objetos, foi possível constatar que eles se encaixam à interoperabilidade, já que se desenvolvem igualmente em diferentes plataformas. Dessa maneira, assim como Leffa explica, os OED analisados mantiveram uma mesma aparência externa de um ambiente digital para outro, ainda que existissem mudanças em suas estruturas internas para que fosse possível alcançar o objetivo inicial de adaptação.

A quarta e última característica, a recuperabilidade, não se aplica a nenhum dos OED analisados, pois se trata de um sistema de catalogação para que os usuários encontrem os objetos desejados de maneira mais rápida e fácil. Nesse sistema, seriam

3 É importante ressaltar que Leffa desenvolveu esse artigo refletindo acerca dos Recursos Educacionais Abertos (REA) que se opõe à cultura das editoras de coleções didáticas. Para maiores informações sobre o REA, recomenda-se a leitura integral de Leffa (2006). 
catalogados descritores para uma busca mais assertiva incluindo o título do objeto educacional, o nome do autor, algumas palavras-chave, permitindo, em alguns casos, a busca por qualquer um desses descritores. Como dito anteriormente, os OED selecionados são disponibilizados pela editora e, portanto, não são inseridos em repositórios públicos aos quais qualquer usuário teria a acesso. Sendo assim, como o objetivo dessa característica é facilitar o acesso do professor à atividade que ele deseja por meio de uma catalogação na qual os OED ficariam disponíveis, podemos afirmar que essa não se enquadra nos objetos. Além disso, faz-se relevante explicar que os OED são produzidos juntamente com os livros didáticos, por esse motivo, com a renovação dos livros didáticos, há também uma renovação de objetos educacionais e os que não estarão mais em uso não são disponibilizados no site da editora. Por fim, observamos que não é viável pensar em recuperabilidade a partir dos objetos educacionais digitais selecionados e analisados.

Diante disso, foi possível analisar que embora uma delas - recuperabilidade - não seja contemplada por nenhum dos objetos, as características restantes - granularidade, reusabilidade e interoperabilidade - são contempladas por todos os OED investigados. Dessa forma, os objetos escolhidos podem ser compreendidos como objetos educacionais digitais, tendo em vista que se encaixam em três das quatro características importantes de um OED.

Entretanto, indo além dessas propriedades, a observação detalhada desses materiais promoveu outras reflexões e questionamentos; pois, apesar de enquadrarem-se na definição de um OED, não proporcionam o desenvolvimento das habilidades linguísticas dos estudantes, com vistas aos multiletramentos, já que alguns deles trazem uma abordagem tradicional e estática de ensino. Esse fato instigou a próxima seção, que apresenta uma descrição e uma análise mais detalhada desses objetos.

\section{Análise dos objetos educacionais digitais na obra Linguagem e Interação a partir dos fundamentos teórico-metodológicos do ensino de Língua Materna}

Para a investigação e a análise dos OED em questão, observando-se a adequação aos pressupostos de ensino de língua materna, optou-se, em vez de realizar uma reflexão isolada de cada uma delas, em agrupá-las em dois eixos, conforme suas características e objetivos. O primeiro eixo é referente ao ensino da gramática normativa do Português e o segundo, referente ao trabalho com os gêneros textuais. Compreende-se que uma análise assim desenvolvida possibilita uma aproximação entre os objetos digitais que se enquadram em um mesmo eixo para que à medida que forem surgindo os aspectos característicos seja possível ressaltar os aportes teóricos necessários.

\subsection{Os OED da coleção Linguagem e Interação com foco nos conhecimentos gramaticais}

Os objetos digitais intitulados OED I - Tipos de sujeito e OED II - Emprego da vírgula foram agrupados, pois abordam conteúdos que se inserem no campo gramatical de ensino de língua portuguesa. No primeiro deles (Tipos de sujeito), o leitor acessará, após a página inicial que mostra apenas o título do objeto, a introdução, a qual já explica 
que os testes a que ele irá responder são referentes a uma análise do sujeito ou sua não existência em trechos de letras de música, como podemos observar na figura:

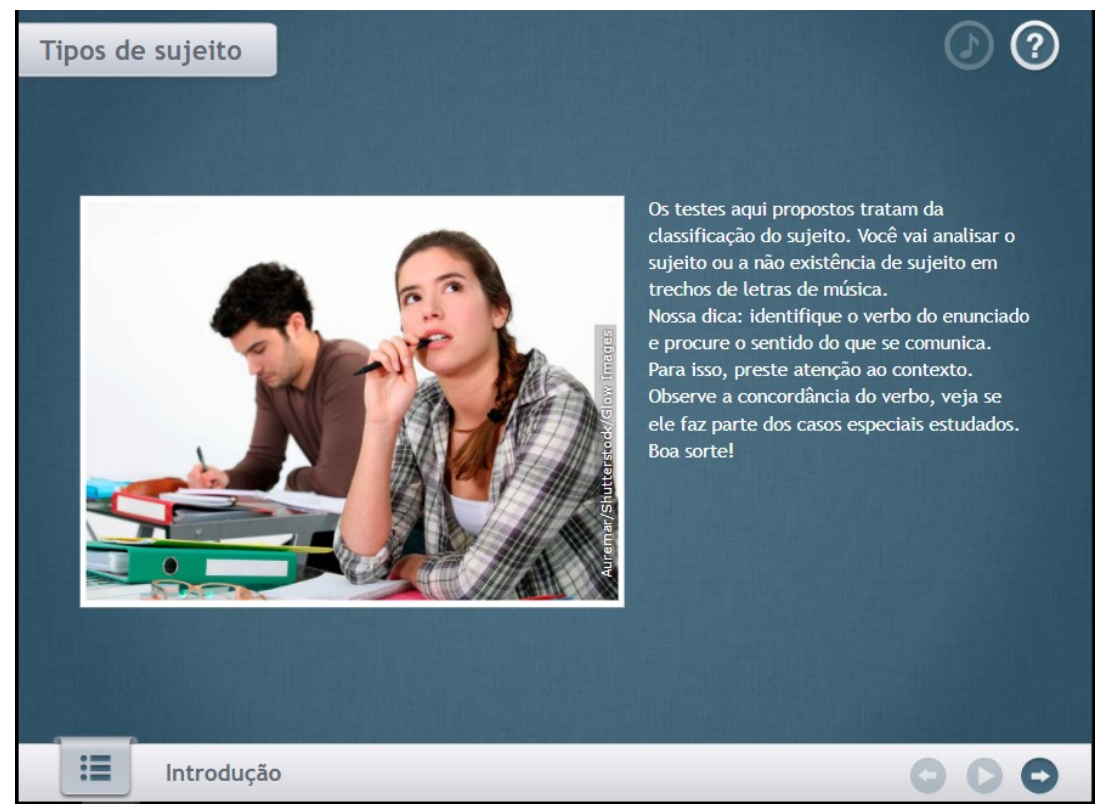

Figura 1: Tipos de sujeito.

Fonte: <http://edocente.plurall.net/support_materials?search\%5Bdidactic_material_id\%5D=1409927\&search \%5Bdisciplines_ids\%5D\%5B\%5D=92\&search\%5Boed_type\%5D\%5B\%5D=0ed\&search\%5Bpage $\% 5 \mathrm{D}=1>$.

Após a introdução, o leitor deve avançar para a página seguinte e, assim, começam os testes nos quais deve marcar a resposta correta. Observemos as imagens da primeira questão:

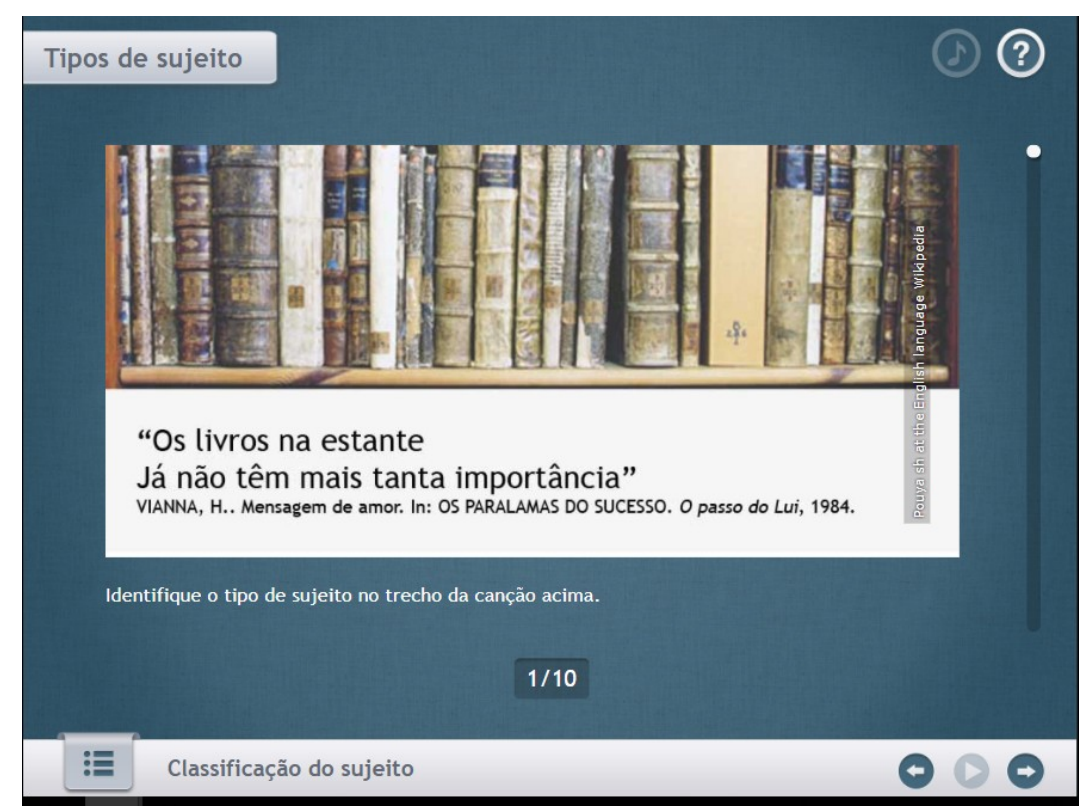

Figura 2: Tipos de sujeito: questão 1/10.

Fonte: <http://edocente.plurall.net/support_materials?search\%5Bdidactic material id $\% 5 D=1409927 \&$ search \%5Bdisciplines_ids\%5D\%5B\%5D=92\&search\%5Boed_type\%5D\%5B\%5D=oed\&search\%5Bpage $\% 5 \mathrm{D}=1>$. 


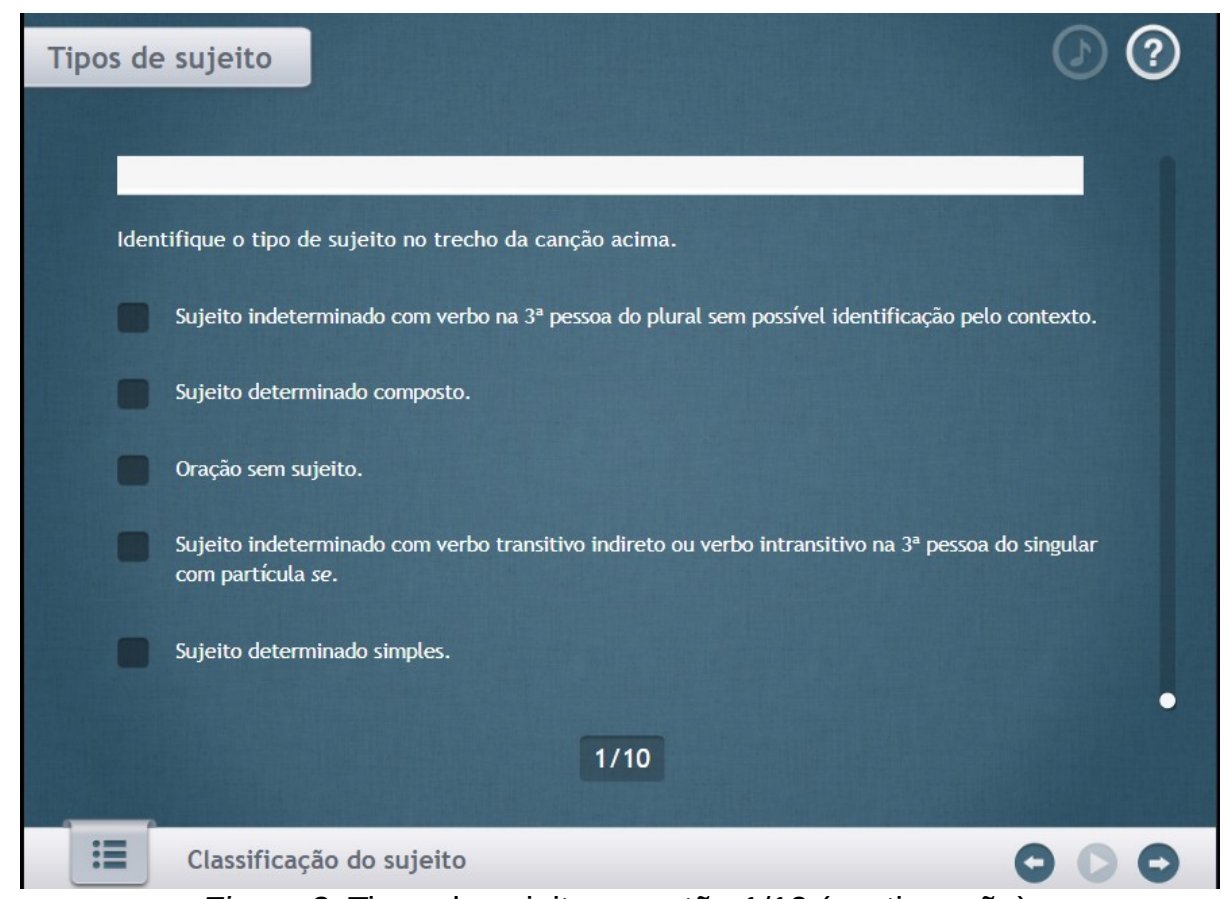

Figura 3: Tipos de sujeito: questão 1/10 (continuação).

Fonte: <http://edocente.plurall.net/support_materials?search\%5Bdidactic_material_id\%5D=1409927\&search \%5Bdisciplines_ids\%5D\%5B\%5D=92\&search\%5Boed_type\%5D\%5B\%5D=oed\&search\%5Bpage\%5D=1>.

Observemos agora o OED - II Emprego da Vírgula. Neste objeto espera-se que os alunos consigam compreender a importância desse sinal de pontuação em um contexto de uso. Ao iniciar o objeto, há um vídeo ao qual o leitor assiste antes de dar início à resolução das questões e é importante salientar que o vídeo não aponta as regras de uso da vírgula, mas demonstra por meio de exemplos como "não espere" e "não, espere" que a presença, a ausência ou a alteração de posição da vírgula pode mudar o sentido que se pretende transmitir.

Também é relevante evidenciar a preocupação deste objeto digital em levantar uma reflexão ao indagar o leitor acerca das razões pelas quais a Associação Brasileira de Imprensa fez uso desse sinal gráfico em seu anúncio, como o próprio OED mostra em sua introdução: 


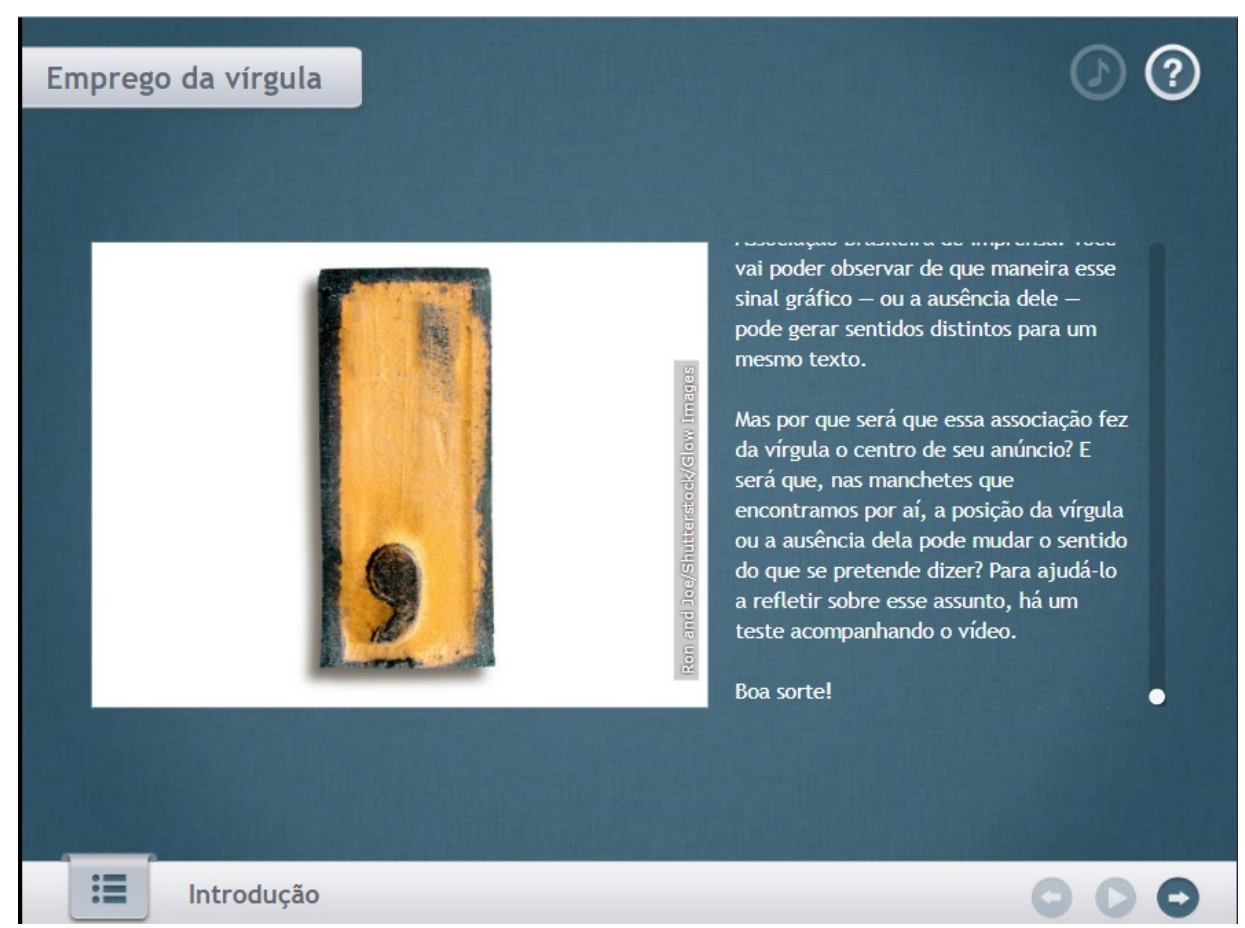

Figura 4: Emprego da vírgula.

Fonte: <http://edocente.plurall.net/support materials?search\%5Bdidactic material_id\%5D=1409927\&search \%5Bdisciplines_ids\%5D\%5B\%5D=92\&search\%5Boed_type\%5D\%5B\%5D=0ed\&search\%5Bpage \%5D=1>.

Dessa maneira, sem impor as condições de uso, o leitor pode refletir sobre as diferentes construções de sentido, tendo em vista suas experiências como falante de português. Além disso, os exemplos dados nas questões também podem propiciar ao leitor momentos de aprendizagem já que as alternativas exploram diferentes sentidos para um mesmo enunciado e, assim, cabe ao leitor compreender qual opção é mais adequada.

Como é possível notar na imagem a seguir, a segunda questão desse objeto digital apresenta o subtítulo de uma notícia e o dever do leitor é encontrar, dentre as alternativas, a frase que melhor funcionaria como título para compor o jornal online. É importante ressaltar que as alternativas se assemelham no que diz respeito às palavras utilizadas, mudando assim predominantemente a posição da vírgula e, dessa forma, o leitor pode observar com maior clareza a diferença entre as possíveis manchetes para uma mesma notícia tendo o conhecimento prévio de qual é a mensagem principal que ela necessita transmitir ao seu público-alvo. Confiramos a informação presente na figura a seguir: 


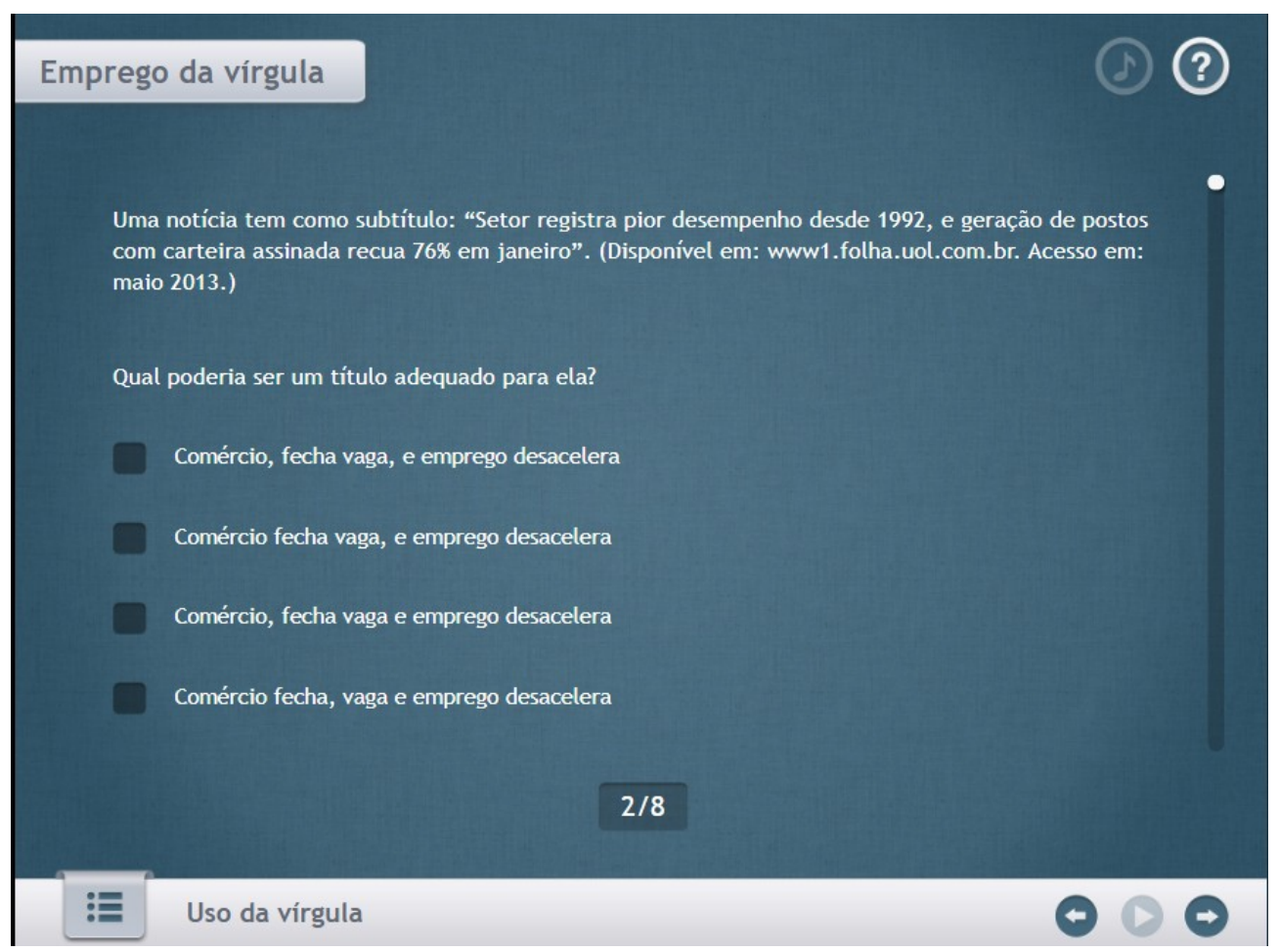

Figura 5: Emprego da Vírgula: questão 2/8.

Fonte: $<$ http://edocente.plurall.net/support_materials?search\%5Bdidactic_material_id\%5D=1409927\&search \%5Bdisciplines_ids\%5D\%5B\%5D=92\&search\%5Boed_type\%5D\%5B\%5D=0ed\&search\%5Bpage \%5D=1> .

Observando os dois OED em questão, é possível depreender que não foram pensados para promover os multiletramentos, pois não visam oportunizar o desenvolvimento cognitivo dos usuários por meio das linguagens que permeiam as formas de produzir textos. Nessa perspectiva, os avanços tecnológicos ampliam e diversificam não somente os modos de disponibilizar e compartilhar informações, mas também de produzi-los e lê-los. Dessa maneira, em relação à pedagogia dos multiletramentos, os OED se mostram falhos já que são baseados em atividades ligadas ainda ao material impresso, ou seja, não exploram os gêneros e as linguagens pertinentes ao uso de um material digital as quais, de acordo com Rojo (2017), precisam ser consideradas pela escola devido à circulação nos ambientes da cultura de massa e digital presente no mundo hipermoderno.

Verifica-se, inclusive, que o OED I não se mostra pertinente a nenhuma recomendação para o ensino contemporâneo, visto que foi desenvolvido tendo como guia as noções de ensino de língua referentes à gramática prescritiva, trabalhando apenas com exercícios de classificação e nomenclaturas. De acordo com Antunes (2007), língua e gramática são coisas distintas e compreender que uma língua é constituída apenas pela gramática é um ato de ingenuidade, além de uma concepção errônea já que para conhecer uma língua não basta dominar totalmente sua gramática (prescritiva). Segundo a autora, a língua é uma atividade interativa, direcionada para a comunicação social e, por esses motivos, apenas o conhecimento gramatical não basta. Sendo assim, trabalhar apenas com listas de exercícios centrados em definições, classificações, nomenclaturas e exercícios em torno de nomes de funções sintáticas - como observamos no OED sobre tipos de sujeito, por exemplo - é claramente um equívoco. 
Além disso, as letras de música são usadas na OED I apenas como pretexto para o trabalho com a gramática tradicional. Sabe-se que o ensino da gramática deve estar articulado a situações de uso e, para tanto, deve-se trabalhar com os diferentes níveis que compõem a língua em uso - isto é, o texto - e seus elementos discursivos, textuais e linguísticos. De acordo com essa concepção, Kemiac e Araújo (2010, p. 52) explicam:

Assim, partindo-se de textos reais, considerados como "enunciados" no sentido bakhtiniano, deve-se propor atividades de reflexão/ análise sobre os recursos linguísticos, observando-se sempre a língua em uso, os fatores extralinguísticos da enunciação que podem ser determinantes para a configuração formal e para os efeitos de sentidos dos elementos linguísticos.

Já o OED II, ao menos, possibilita ao aluno uma reflexão a partir de casos da língua, comparando-os e aplicando-os no contexto de uma manchete de jornal. Não há, portanto, uma ênfase explícita em definições e metalinguagem. De acordo com Kemiac e Araújo ${ }^{4}$ (2010), o ensino da gramática deve acontecer a partir da vivência e da reflexão do aluno sobre os elementos da língua e, na sequência, devem ser explicitados de maneira organizada os conhecimentos que ele produziu. Pensando nesse procedimento, as autoras explicam que o ensino deve:

[...] partir da experimentação, da vivência e da reflexão do aluno acerca dos elementos da língua. Somente após atentar para o uso e os efeitos de sentidos dos recursos linguísticos é que os dois passos seguintes da explicitação ("explicitar de maneira organizada os conhecimentos que produziu") e da sistematização/ avaliação ("ver suas vivências e descobertas contrapostas a alguma teoria já estabelecida") tornam-se possíveis e significativos (KEMIAC; ARAÚJO, 2010, p. 50).

De acordo com Kemiac e Araújo, deve-se promover um raciocínio indutivo possibilitando que o aluno chegue a uma conclusão e, após ser sintetizada organizando os conhecimentos que produziu e as regularidades que inferiu, o professor pode trazer as nomenclaturas e teorias já estabelecidas na língua, mas sem a primazia total como observamos no OED I. Ainda sobre a indução, as autoras dissertam que:

É importante destacar que a indução não apenas pode ser auxiliar no desenvolvimento da capacidade de análise do aluno, como também pode tornar os conhecimentos construídos mais significativos para o aprendiz, já que esses serão resultado da contraposição de sua experiência pessoal às teorias já estabelecidas (KEMIAC; ARAÚJO, 2010, p. 51).

O OED II parece corresponder a essa perspectiva, pois o aluno tem a chance de refletir acerca do uso da vírgula de maneira contextualizada, já que está articulada a gêneros textuais jornalísticos - anúncio publicitário e notícia - a partir de suas vivências e experiências. Nota-se que não há um momento nesse objeto digital dedicado a apresentar

4 As autoras assumem o ensino de Língua Portuguesa por meio da análise linguística, a qual vai além do ensino de Gramática Tradicional. A análise linguística preconiza a articulação à situação de uso e a exploração, nos diferentes níveis, dos recursos que compõem o texto em foco. 
as regras de uso da vírgula na língua, assim como os testes propostos também não se atêm a terminologias gramaticais, mas priorizam os diferentes sentidos que esse sinal gráfico pode exprimir.

Portanto, enquanto o OED I prioriza um ensino de línguas amarrado a suas nomenclaturas, o OED II prioriza as interpretações do aluno que, por meio de reflexões acerca da língua situada - em contextos de uso -, pode compreender as influências desse sinal gráfico bem como desenvolver sua capacidade de atuar em sua vida social. Entretanto, observa-se que ambos os objetos não correspondem aos objetivos esperados para o trabalho com os materiais digitais, ou seja, não promovem a prática pedagógica dos multiletramentos, que busca uma aprendizagem a partir das culturas de referência do estudante, almejando o enfoque crítico e pluralista a fim de contribuir para um desenvolvimento cognitivo por meio das linguagens que permeiam as práticas sociais atuais.

\subsection{Os OED da coleção Linguagem e Interação com foco nos gêneros textuais e as práticas de leitura e escrita}

Os objetos digitais intitulados OED III - Gráficos, OED IV - Entrevista oral, OED V - Texto instrucional, OED - VI Leitura de infográfico e OED - VII Notícia foram agrupados nesta análise por priorizarem o trabalho com os gêneros. No entanto, a fim de facilitar a compreensão, ainda dividimos esse grupo em duas seções: primeiramente analisamos os OED Entrevista oral e Texto instrucional e, em seguida, são analisados os OED nomeados Gráficos, Leitura de infográfico e Notícia.

\subsubsection{OED entrevista oral e texto instrucional}

O OED IV - Entrevista oral pressupõe que o aluno já tenha observado a postura e o comportamento dos indivíduos presentes em entrevistas transmitidas pela televisão. Nesse OED, como a própria introdução sugere, o usuário tem a oportunidade de ouvir uma entrevista radiofônica a fim de perceber que, numa situação comunicativa como essa, cada um desempenha um papel específico, gerando determinados comportamentos nos demais participantes. O vídeo disponível faz parte da série Meu país, nosso mundo, da produtora TAL (Televisión América Latina) que pretende conscientizar a população acerca de questões ambientais. Após a execução do áudio, o leitor deve responder a cinco questões sobre o gênero, por exemplo: 


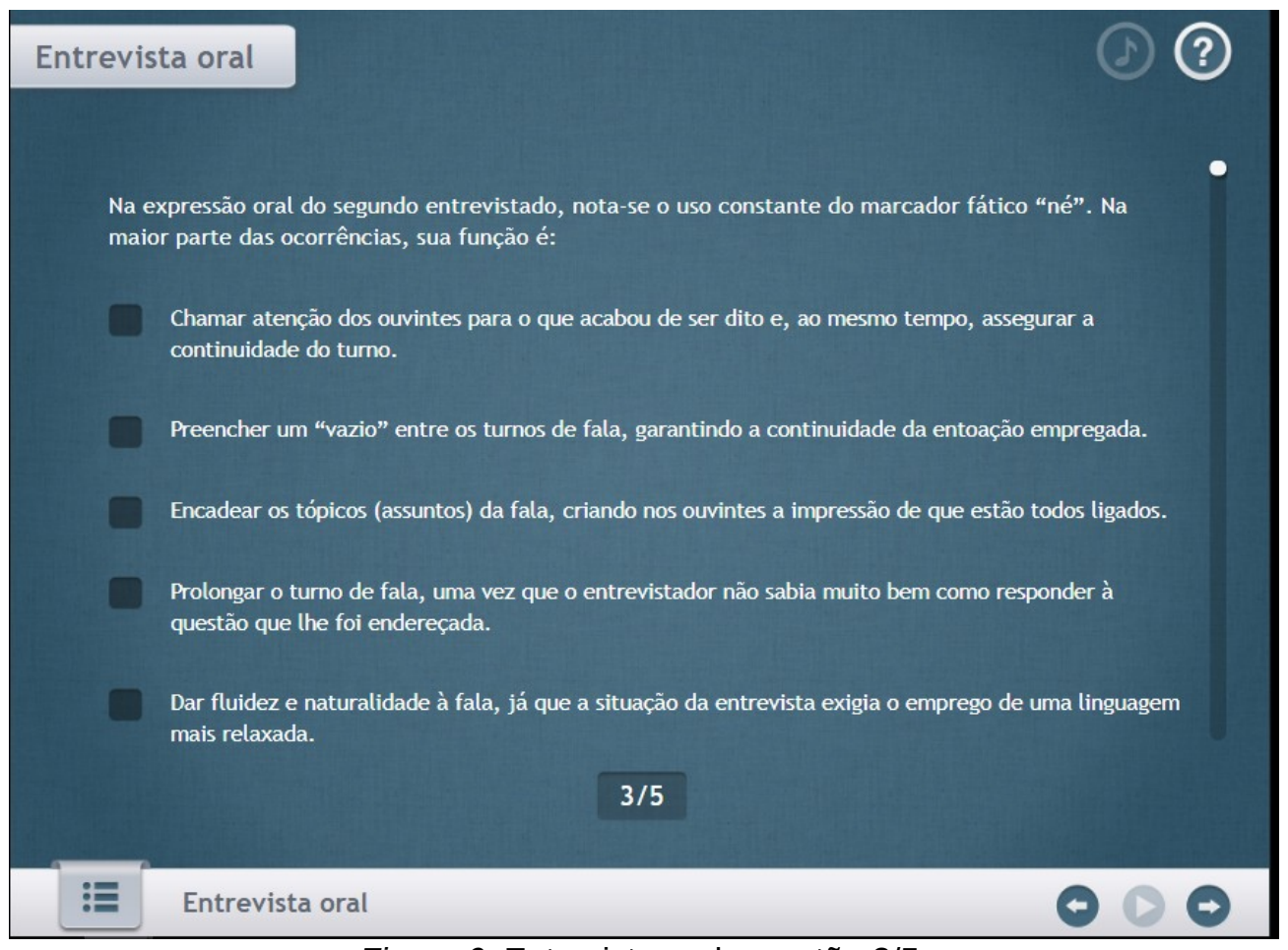

Figura 6: Entrevista oral: questão 3/5.

Fonte: <http://edocente.plurall.net/support materials?search\%5Bdidactic material id\%5D=1409927\&search \%5Bdisciplines_ids\%5D\%5B\%5D=92\&search\%5Boed_type\%5D\%5B\%5D=oed\&search\%5Bpage\%5D=1>.

Como se observa na Figura 6, a atividade pauta-se em explorar os elementos gestuais e orais presentes na entrevista radiofônica a qual o usuário teve acesso anteriormente, mas não parece favorecer de fato o gênero entrevista oral deixando de evidenciar aspectos presentes nesse gênero ao não promover um entendimento de leitura e escrita do mesmo.

O OED V - Texto instrucional tem início com uma breve explicação da organização desse gênero textual e, para esclarecer esses aspectos, o leitor deve assistir a um vídeo Usando mapas para navegar, que demonstra o uso de alguns textos instrucionais específicos elaborados com a finalidade de fornecer orientações de localização espacial para usuários que desejam se movimentar por meio de um GPS, por exemplo. O OED afirma que o vídeo em si se insere em uma qualificação de gênero expositivo e instrucional e que os testes subsequentes se baseiam nos recursos da linguagem verbal e da linguagem visual observados, ressaltando alguns recursos empregados em textos dessa natureza: 


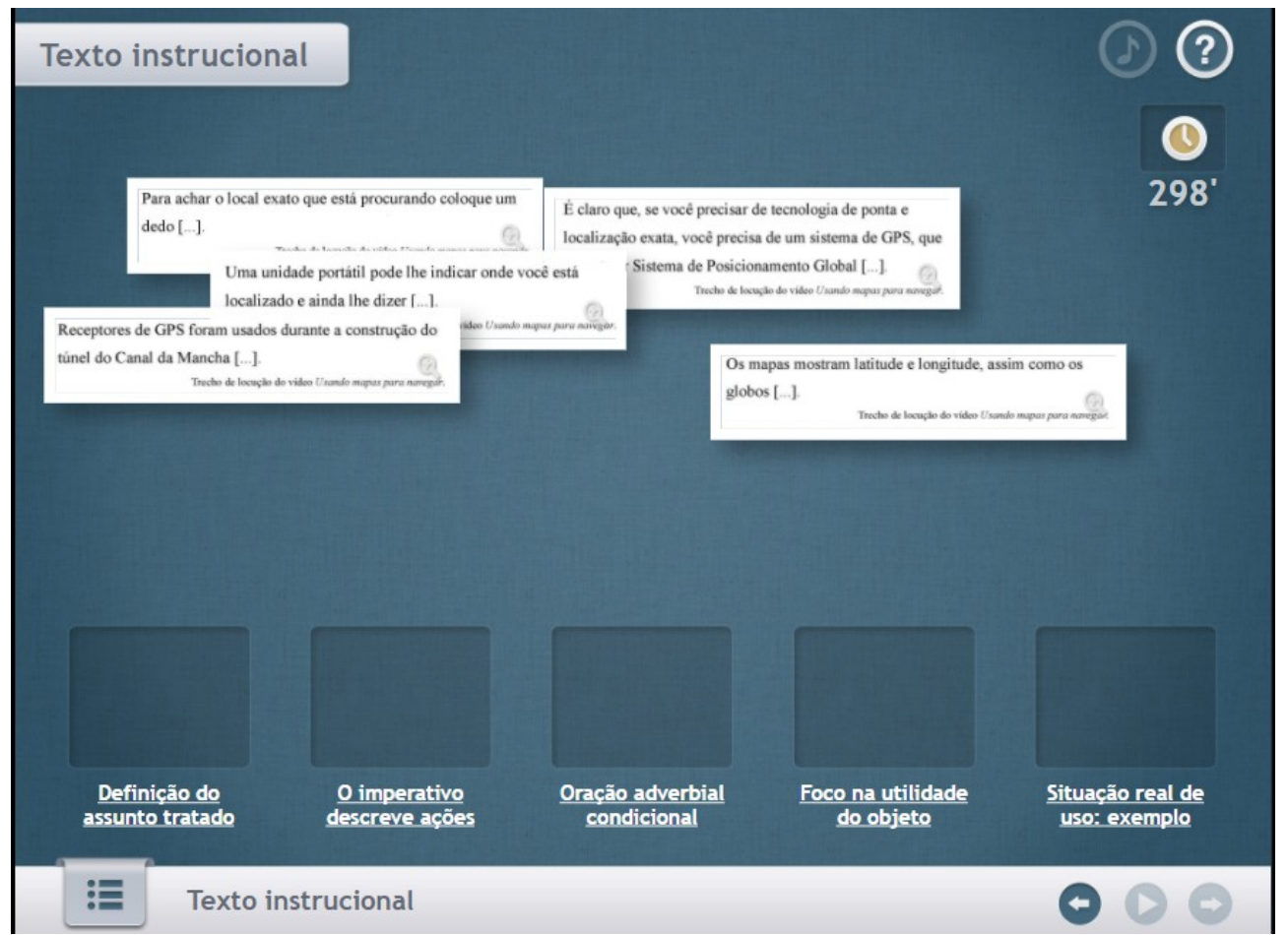

Figura 7: Texto instrucional.

Fonte: $<$ http://edocente.plurall.net/support materials?search\%5Bdidactic material id\%5D=1409927\&search \%5Bdisciplines ids\%5D\%5B\%5D=92\&search\%5Boed_type\%5D\%5B\%5D=oed\&search\%5Bpage \%5D=1>.

Como se pode observar na imagem acima, o jogo consiste em ligar os segmentos retirados do vídeo de acordo com os tópicos expostos pelo objeto digital.

Sabe-se que o ensino de língua materna na perspectiva dos multiletramentos pressupõe o desenvolvimento de conhecimentos não apenas para que o aluno possa lidar com os aparatos tecnológicos, mas, sobretudo, para que proporcionem a construção de outros saberes, por meio da reflexão sobre os gêneros, sejam eles próprios ou não dos contextos digitais. Segundo Marcuschi (2008, p. 155):

Os gêneros textuais são os textos que encontramos em nossa vida diária e que apresentam padrões sociocomunicativos característicos definidos por composições funcionais, objetivos enunciativos e estilos concretamente realizados na integração de forças históricas, sociais, institucionais e técnicas. Em contraposição aos tipos, os gêneros são entidades empíricas em situações comunicativas e se expressam em designações diversas, constituindo em princípio listagens abertas.

Assim, os gêneros são entidades comunicativas, e não formais, nas quais predominam aspectos relativos a funções, propósitos, ações e conteúdos. Nesse sentido, uma atividade que objetive o trabalho com um gênero deve priorizar seus aspectos sociocomunicativos, o que não parece ocorrer nesses OED.

O OED IV - Entrevista oral, apesar de possuir esse título, centrou-se em elementos gestuais e orais (como o uso do marcador conversacional né) dos participantes da entrevista, deixando a desejar no que diz respeito à compreensão do gênero entrevista oral. Claramente, há a possibilidade de trabalhar com tais elementos, no entanto, a 
questão é que os mesmos não são típicos apenas da entrevista oral, mas de qualquer oralidade. Talvez a inadequação se dê no próprio nome do objeto ou seus objetivos, visto que se trata de um áudio.

No que se refere ao OED $V$ - Texto instrucional, observa-se apenas uma reprodução do vídeo assistido, pois a atividade consiste em organizar alguns trechos do vídeo de acordo com os tópicos (definição do assunto tratado; o imperativo descreve ações; oração adverbial condicional; foco na utilidade do objeto; e situação real de uso: exemplo) elencados pelo objeto. Essa atividade trata o texto como uma estrutura rígida que possui correlações específicas, ignorando seus aspectos funcionais. No entanto, entende-se que o equívoco do objeto centra-se na atividade e não de maneira geral. 0 vídeo que os alunos deverão assistir, por exemplo, demonstra claramente as funções e as ações de instrumentos que auxiliam na localização dos usuários, mas a atividade proposta não aproveita positivamente as compreensões que podem ser geradas pelo aluno. Dessa forma, escolhe-se reduzir a importância do gênero textual de entidade comunicativa para apenas uma entidade formal e linguística.

Uma questão que não pode ser deixada de lado é que esses dois OED aqui discutidos apresentam a multimodalidade em essência. Esse fato merecia uma abordagem via multiletramentos, oportunizando ao professor e alunos o desenvolvimento de capacidades de leitura e produção que vão muito além da compreensão e produção de textos escritos incorporando a leitura de imagens, diagramas, vídeos e áudio. Sobre isso, Dionísio (2014) discorre acerca da importância de trabalhar com a multimodalidade na perspectiva dos multiletramentos:

\begin{abstract}
Multiletrar é, portanto, buscar desenvolver cognitivamente nossos alunos, uma vez que a nossa competência genérica se constrói e se atualiza através das linguagens que permeiam nossas formas de produzir textos. Assim, as práticas de multiletramentos devem ser entendidas como processos sociais que se interpõem em nossas rotinas diárias (DIONISIO, 2014, p. 41).
\end{abstract}

No entanto, como se pode observar, a multimodalidade foi completamente desconsiderada nos OED analisados nesta seção, visto que não se promove o desenvolvimento da compreensão por meio das linguagens que permeiam as atuais formas de produzir textos.

\title{
4.2.2 OED gráficos, infográfico e notícia
}

No OED Gráficos, o leitor acessa a introdução, a qual explica o que são os textos icônico-verbais e, em seguida, menciona que o usuário assistirá a um vídeo sobre uma competição entre duas equipes e que os resultados serão apresentados por meio de gráficos de colunas. Ao final da introdução, afirma-se que após o vídeo há um teste sobre os elementos fundamentais dos gráficos. Vejamos uma das imagens da introdução deste OED: 


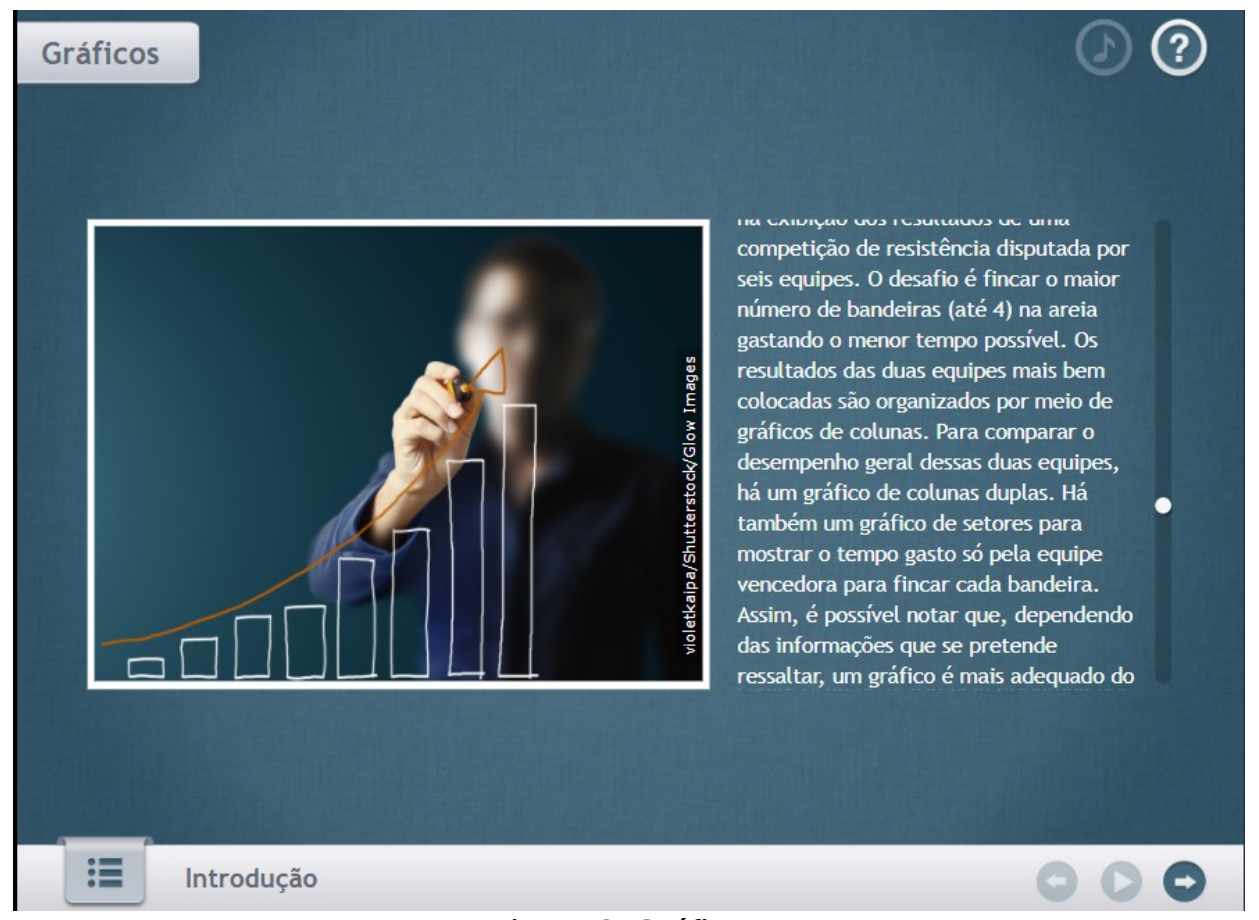

Figura 8: Gráficos.

Fonte: <http://edocente.plurall.net/support_materials?search\%5Bdidactic_material_id\%5D=1409926\&search \%5Bdisciplines_ids\%5D\%5B\%5D=92\&search\%5Boed_type $\% 5 \mathrm{D} \% 5 \mathrm{~B} \% 5 \mathrm{D}=$ oed $>$.

$\mathrm{Na}$ sequência, o leitor encontra questões de múltipla escolha para responder acerca dos gráficos. Observemos em seguida, a imagem da primeira questão:

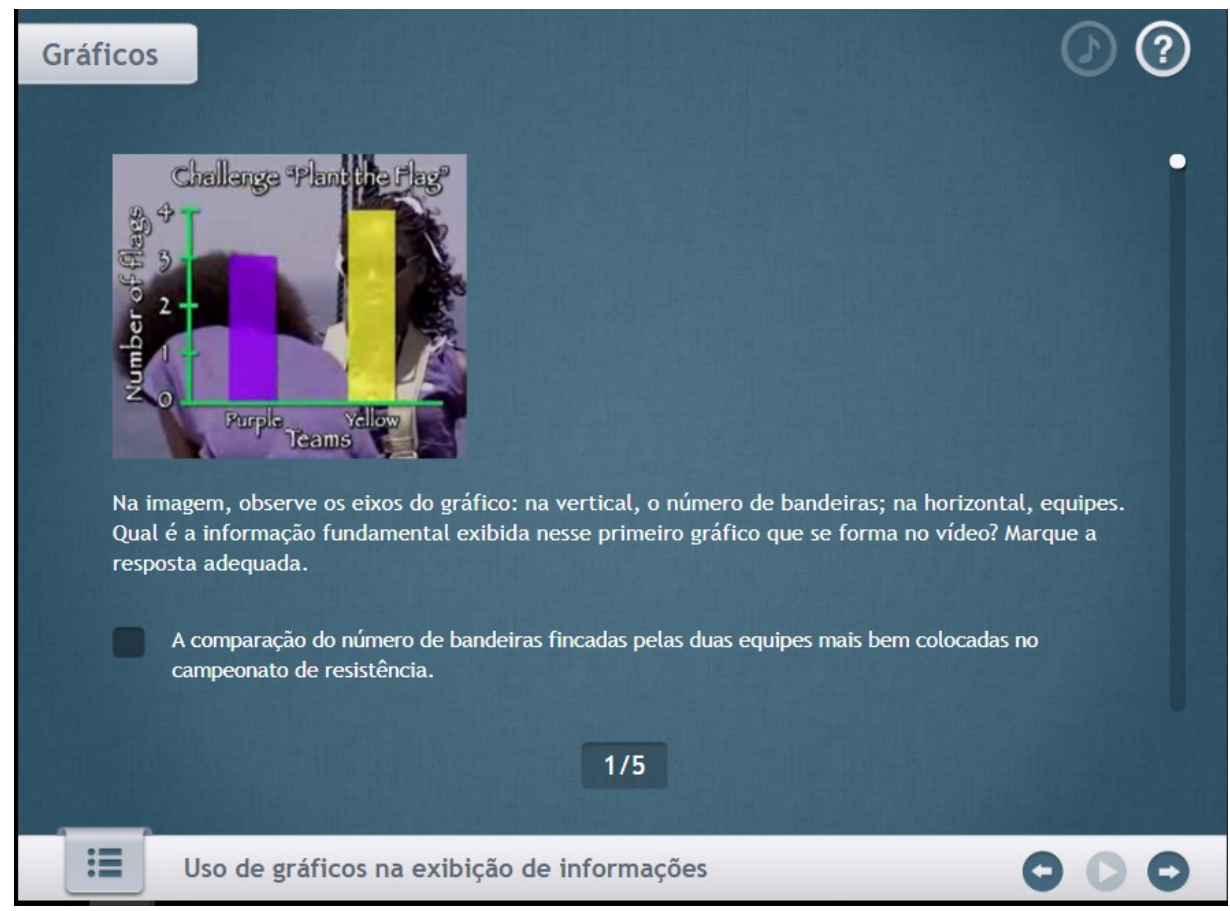

Figura 9: Gráficos: questão 1/5.

Fonte: <http://edocente.plurall.net/support_materials?search\%5Bdidactic material_id\%5D=1409926\&search \%5Bdisciplines_ids\%5D\%5B\%5D=92\&search\%5Boed_type $\% 5 \mathrm{D} \% 5 \mathrm{~B} \% 5 \mathrm{D}=$ oed $>$. 
Como visto anteriormente, o enunciado da questão solicita a interpretação do gráfico dado a fim de compreender qual seria a informação principal proposta pelo mesmo. Já na questão três, por exemplo, exige-se que o aluno reflita sobre como uma configuração diferente de gráfico gera uma exposição de resultados de maneira distinta do apresentado na questão 1:

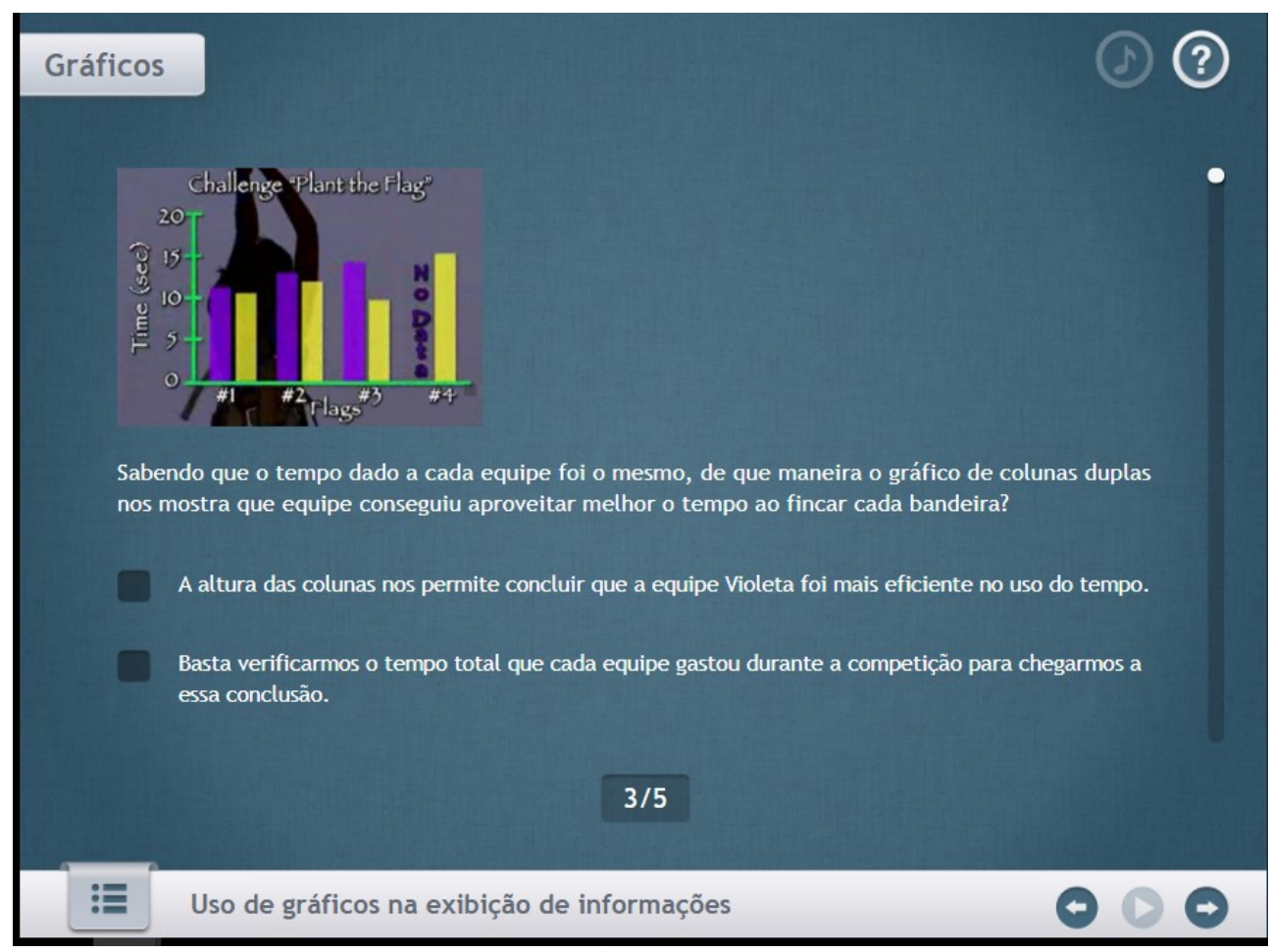

Figura 10: Gráficos: questão 3/5.

Fonte: $<$ http://edocente.plurall.net/support_materials?search\%5Bdidactic_material_id\%5D=1409926\&search \%5Bdisciplines ids\%5D\%5B\%5D=92\&search\%5Boed type $\% 5 \mathrm{D} \% 5 \mathrm{~B} \% 5 \mathrm{D}=$ oed $>$.

O OED VI - Leitura de infográfico, em sua introdução, aproxima textos de vulgarização científica de infográficos, explicando que esse é um gênero textual que integra linguagens visual e verbal ao apresentar de maneira sintética um determinado assunto. Ao avançar o objeto digital, o usuário entra em contato com um infográfico sobre o sistema circulatório - apresentando uma explicação inicial - no qual ao clicar nos tópicos principais esses são iluminados ganhando destaque. Observemos: 


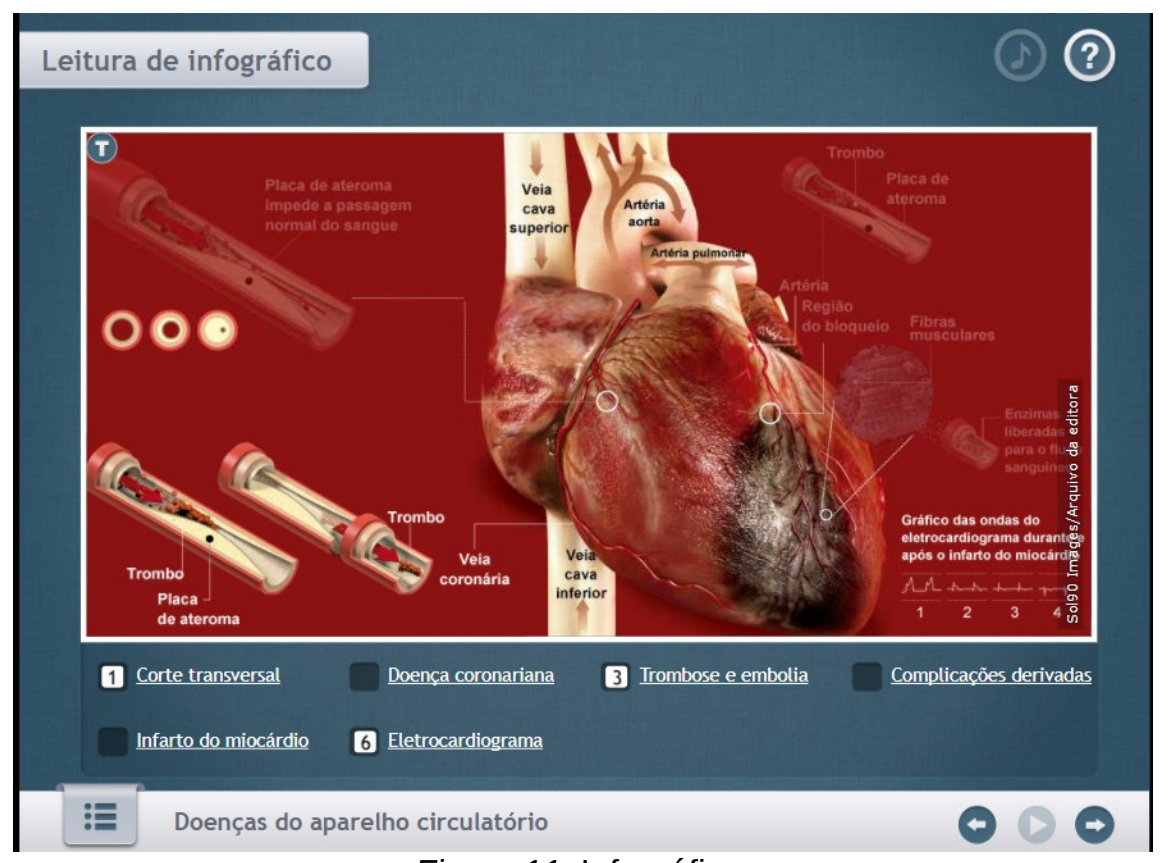

Figura 11: Infográfico.

Fonte: <http://edocente.plurall.net/support_materials?search\%5Bdidactic material_id\%5D=1409927\&search \%5Bdisciplines_ids\%5D\%5B\%5D=92\&search\%5Boed_type\%5D\%5B\%5D=oed\&search\%5Bpage $\% 5 \mathrm{D}=1>$

Além disso, ao passo que vai participando da construção da legenda do infográfico, o usuário também pode, ao passar o cursor do mouse pelos tópicos, obter breves informações referentes aos temas selecionados sobre o sistema circulatório, que é o tema principal desse objeto digital.

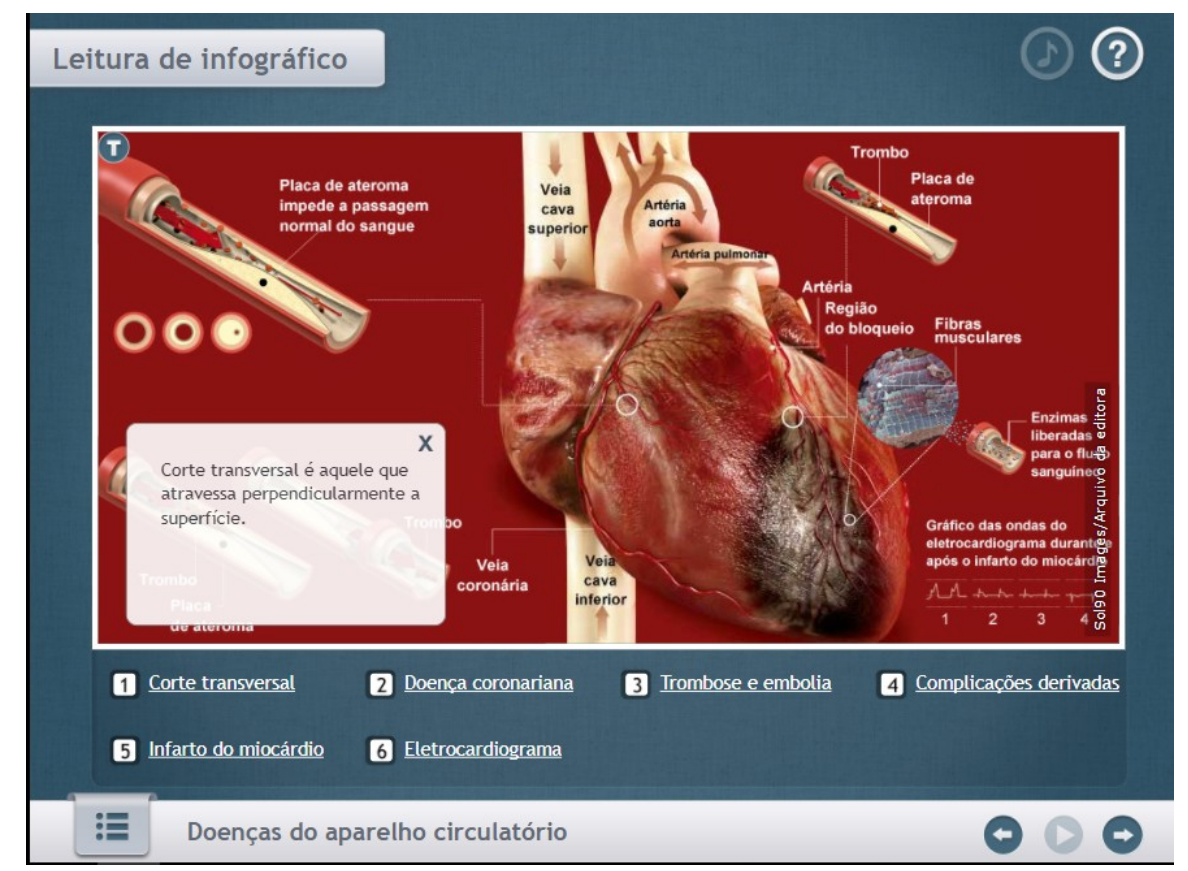

Figura 12: Infográfico: caixas de informações.

Fonte: <http://edocente.plurall.net/support_materials?search\%5Bdidactic_material_id\%5D=1409927\&search \%5Bdisciplines ids\%5D\%5B\%5D=92\&search\%5Boed_type\%5D\%5B\%5D=oed\&search\%5Bpage\%5D=1>. 
Em seguida, o leitor pode responder a quatro (4) questões referentes à função do gênero textual infográfico em foco como podemos observar na imagem a seguir:

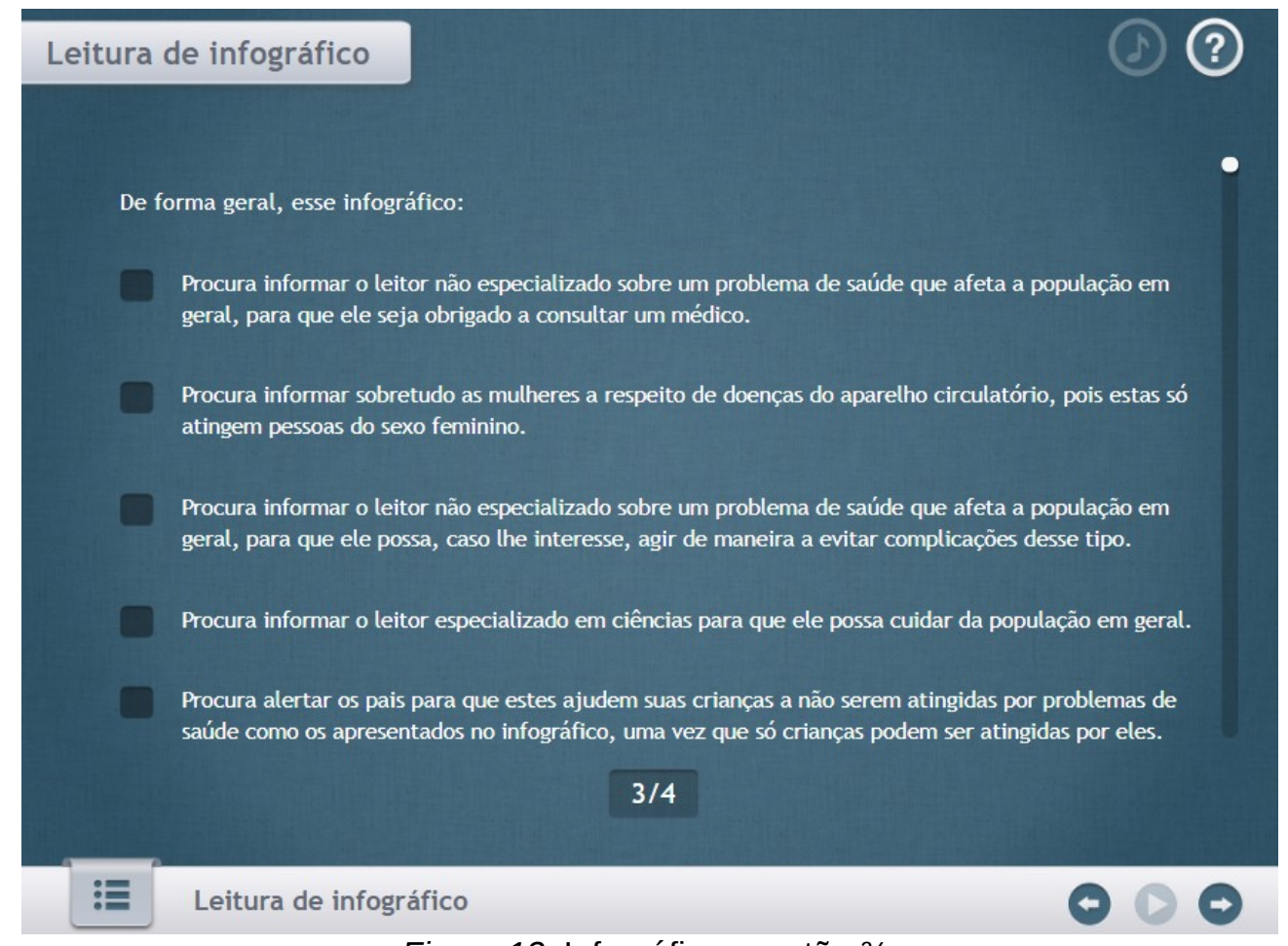

Figura 13: Infográfico questão 3/4.

Fonte: <https://pluralcontent.s3.amazonaws.com/OED/AT_PORT_LI/PORT_LI2_11/index.html>.

O OED - VII Notícia inicia-se com uma contextualização acerca de aspectos importantes dos textos jornalísticos, mostrando diferenças e semelhanças entre reportagem e notícia. De acordo com a própria introdução do objeto, o usuário pode conhecer as principais partes de uma notícia compreendendo mais sobre as estruturas que a compõem. Para tanto, ao avançar a página do objeto, o aluno entra em contato com uma notícia na qual, ao clicar nos quadrados referentes aos termos evidenciados, a estrutura correspondente ganha destaque, formando, assim, uma legenda. 


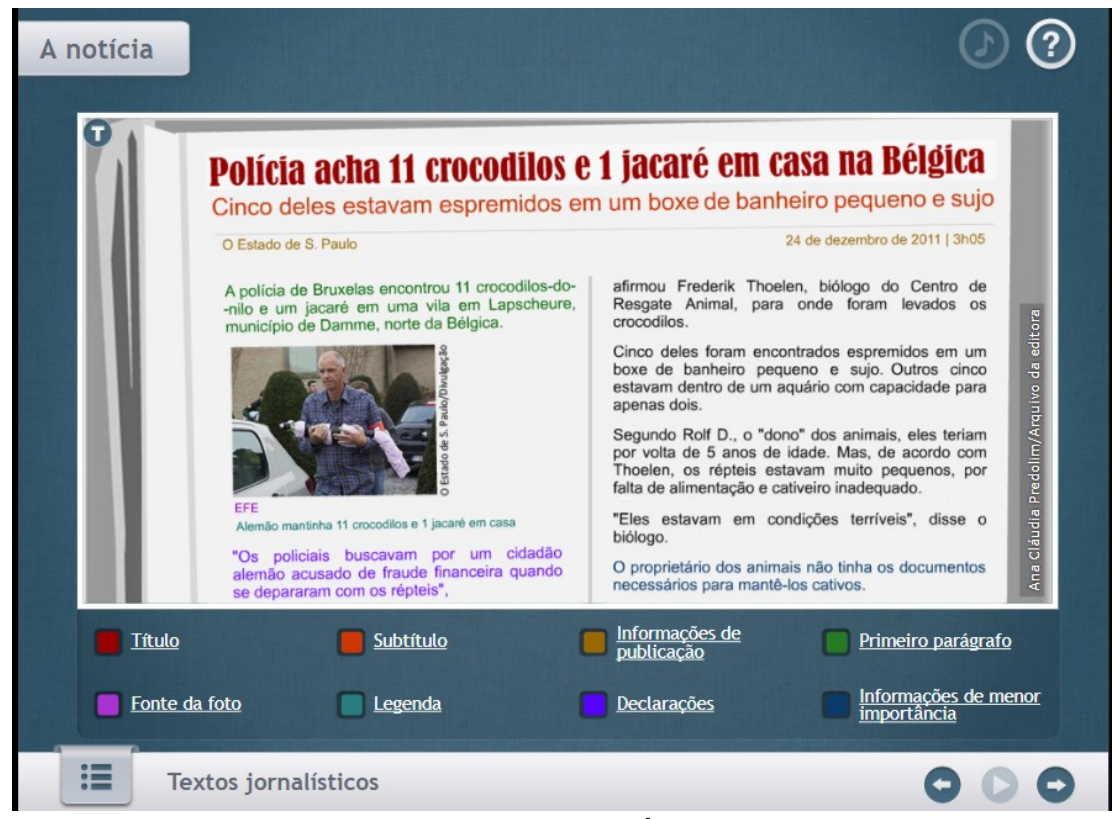

Figura 14: Notícia.

Fonte: <http://edocente.plurall.net/support_materials?search\%5Bdidactic_material_id\%5D=1409928\&search \%5Bdisciplines_ids $\% 5 \mathrm{D} \% 5 \mathrm{~B} \% 5 \mathrm{D}=92 \&$ search $\% 5 \mathrm{Boed}$ type $\% 5 \mathrm{D} \% 5 \mathrm{~B} \% 5 \mathrm{D}=$ oed $>$.

Também é possível observar, assim como no OED VI - Leitura de infográfico, que ao construir a legenda da notícia, o estudante também pode, ao passar o cursor do mouse pelos termos, obter breves informações referentes aos tópicos selecionados sobre as partes de uma notícia tendo em vista o que se espera encontrar em cada tema buscando uma ampla compreensão desse gênero textual. A imagem a seguir exemplifica o que foi exposto:

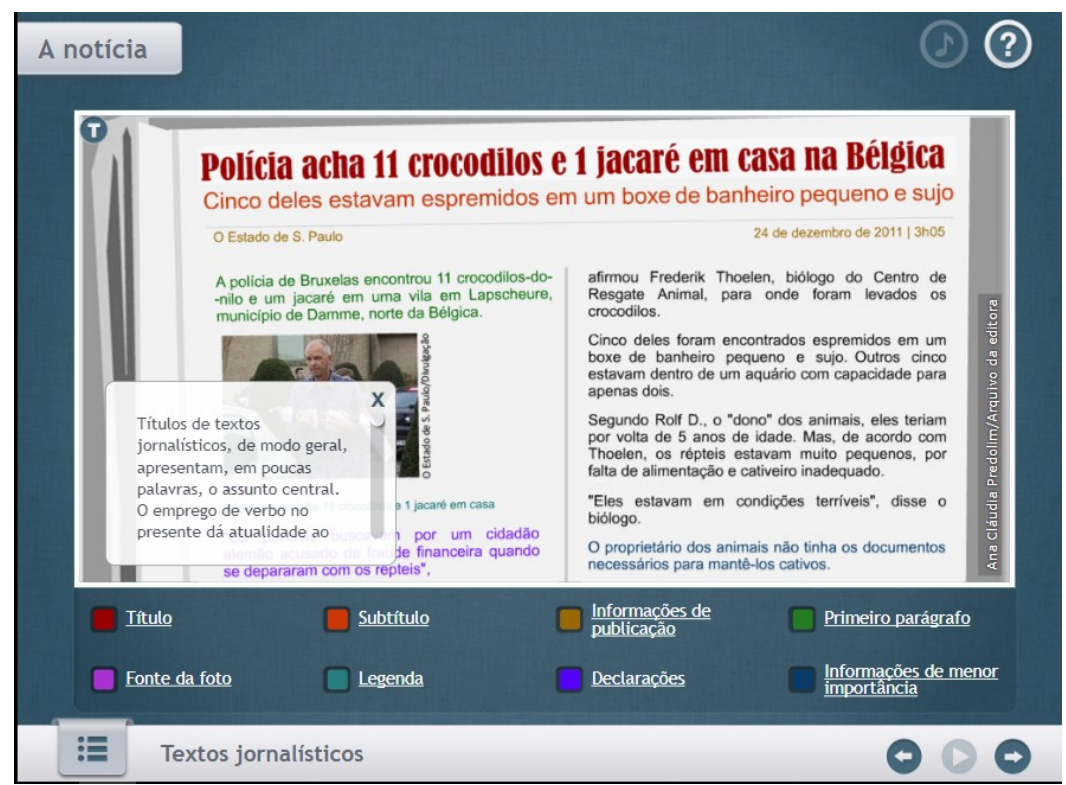

Figura 15: Notícia: caixas de informações.

Fonte: $<$ http://edocente.plurall.net/support_materials?search\%5Bdidactic_material_id\%5D=1409928\&search \%5Bdisciplines_ids\%5D\%5B\%5D=92\&search\%5Boed_type\%5D\%5B\%5D=oed>. 
Refletindo sobre esses OED, é possível analisar que eles apresentam-se pertinentes para o ensino de língua, tendo em vista que as características dos gêneros em questão são exploradas a partir de seu contexto social. Esses objetos buscam propiciar o entendimento sobre a tipicidade de um gênero por meio de suas funções, propósitos e ações, mostrando ao usuário como eles se comportam em práticas comunicativas.

Pode-se notar que o OED III - Gráficos cumpre seu papel de demonstrar que os gêneros não funcionam como um produto acabado, já que, ao longo das atividades propostas, os alunos entram em contato com diferentes tipos de gráficos, por exemplo, a partir de um mesmo conteúdo inicial (vídeo) que representa uma competição entre duas equipes. Dessa maneira, eles podem refletir sobre como uma situação específica influencia sua representação em determinado tipo de gráfico. As questões realizadas pelo objeto propiciam interpretações acerca do conteúdo apresentado e, assim, os gráficos tornam-se um evento comunicativo enfatizando as habilidades de compreensão e os modos de produção de sentido.

Vale lembrar aqui que Marcuschi (2008) aponta o gênero textual como um indicador importante, pois a compreensão, o trato e a produção de determinados gêneros não correspondem a outros e, por isso, os gêneros não são simples formas textuais, mas "formas de ação social". O OED Notícia pode ser um bom exemplo para tanto já que, ao utilizar esse objeto educacional, o leitor é exposto a textos os quais fazem parte de sua vida cultural cotidiana. Além disso, o modo como o objeto trabalha a compreensão do gênero - criando legendas, explicando cada parte evidenciada, mostrando sua função e o que um leitor pode encontrar - auxilia o aluno a entender que cada gênero textual possui uma maneira particular de ser compreendido e constituir-se.

No que concerne ao OED Leitura de Infográfico, pode-se verificar que ele também trabalha com o gênero textual e sua função social ao levantar questionamentos acerca do infográfico apresentado, promovendo reflexões sobre qual é o seu propósito e qual é a produção de sentido das imagens. Esse OED, assim como o anterior, envolve atividades nas quais os usuários têm a chance de compreender o funcionamento dos gêneros em situações comunicativas autênticas cotidianas.

Além disso, verifica-se que a multimodalidade é explorada positivamente nesses materiais digitais. Ao compreender que esses OED apresentam fenômenos multimodais, considera-se o grau de informatividade visual dos gêneros abordados e reconhece-se uma nova forma de interação entre leitor e texto que resulta de uma relação íntima entre o leitor, o texto e as inovações tecnológicas (DIONÍSIO, 2011).

Em relação à característica de informatividade visual, podemos destacar as imagens representativas - vídeo, gráfico, notícia, imagens do aparelho circulatório - sem nos esquecermos da importância das cores que são utilizadas tanto no OED Gráficos como meio de diferenciar as barras pertencentes a cada equipe - quanto nos OED Infográfico e Notícia, os quais são essenciais para a configuração das legendas. Essas características observadas corroboram, de certo modo, o conceito da multimodalidade que encara o material digital como uma oportunidade de integrar modos de linguagem por meio desses dispositivos. Assim, atribui-se certa importância a essa linguagem midiática, que dispõe de formas de representação de texto incluindo texto escrito, som e imagem (fixa ou em movimento), ao passo que está atribuindo sentido aos objetos digitais. Portanto, a partir do pressuposto de que esses OED servem-se da multimodalidade, 
entende-se que se remetem, concomitantemente, ao conceito dos multiletramentos, pois se apresentam unindo modos de linguagem, assim como os gêneros multimodais que, de acordo com Rojo (2017), devem envolver as diferentes modalidades dessa linguagem midiática tão presente nesta era digital.

\section{Discussão dos resultados}

Uma vez que se têm os resultados obtidos durantes as análises dos OED, tanto em relação aos princípios de Leffa (2006) quanto ao ensino de Língua Portuguesa, é possível, então, analisá-los com vistas a alguns resultados.

No Quadro 1 a seguir, para evidenciar a compreensão e a síntese dessa breve análise, é mostrado como os objetos em foco se enquadram em cada característica estabelecida por Leffa (2006):

Quadro 1: síntese da análise dos OED.

\begin{tabular}{|l|c|c|c|c|}
\hline \multicolumn{1}{|c|}{ OED } & Granularidade & Reusabilidade & Interoperabilidade & Recuperabilidade \\
\hline $\begin{array}{l}\text { Tipos de } \\
\text { Sujeito }\end{array}$ & $\mathrm{X}$ & $\mathrm{X}$ & $\mathrm{X}$ & \\
\hline $\begin{array}{l}\text { Emprego da } \\
\text { Vírgula }\end{array}$ & $\mathrm{X}$ & $\mathrm{X}$ & $\mathrm{X}$ & \\
\hline Gráficos & $\mathrm{X}$ & $\mathrm{X}$ & $\mathrm{X}$ & \\
\hline Entrevista oral & $\mathrm{X}$ & $\mathrm{X}$ & $\mathrm{X}$ & \\
\hline $\begin{array}{l}\text { Texto } \\
\text { instrucional }\end{array}$ & $\mathrm{X}$ & $\mathrm{X}$ & $\mathrm{X}$ & \\
\hline $\begin{array}{l}\text { Leitura de } \\
\text { Infográfico }\end{array}$ & $\mathrm{X}$ & $\mathrm{X}$ & \\
\hline Notícia & & & \\
\hline
\end{tabular}

Fonte: dos autores.

Essa análise inicial sugere que os OED em questão são satisfatórios ao ensino de língua. Entretanto, é importante destacar que ela apenas caracteriza um objeto digital como tal. Por isso, em seguida, foi realizada uma outra análise pautada na compreensão de como os OED se apresentam a partir dos fundamentos teórico-metodológicos do ensino de língua materna e se eles contemplavam (ou não) o desenvolvimento de habilidades linguísticas a partir da pedagogia dos multiletramentos. Os resultados mostram que em relação aos fundamentos teórico-metodológicos, os OED, em sua maioria, foram percebidos como ainda atrelados a um ensino tradicional e estático, que não promovem a prática dos multiletramentos.

Observando-se com mais atenção cada um dos OED, pode-se apontar que os objetos referentes aos conhecimentos gramaticais - Tipos de Sujeito e Emprego da vírgula - não se apresentam favoráveis aos objetivos esperados para a prática com os materiais digitais, ou seja, não promovem a pedagogia dos multiletramentos, desconsiderando, assim, as diversas linguagens que permeiam as práticas sociais 
contemporâneas. Isto porque o OED - Tipos de sujeito prioriza, claramente, um ensino preso a nomenclaturas tendo em vista seu objetivo de classificação de terminologias e o OED-Emprego da vírgula, apesar de propiciar as interpretações do aprendiz por meio de reflexões acerca da língua situada (em contextos de uso), também não envolve a multimodalidade e, de acordo com Coscarelli (2009) e Rojo (2017), não se utiliza da multimodalidade que as TDIC oferecem.

Em relação aos OED referentes aos gêneros textuais e às práticas de leitura e escrita, os objetos Entrevista oral e Texto instrucional tratam o texto como um produto acabado funcionando como um simples artefato pronto, quando, na verdade, segundo Marcuschi (2008), ele é um processo e precisa ser compreendido como uma atividade comunicativa. Essa perspectiva do autor sugere que se compreenda o texto como um evento comunicativo para o qual convergem ações linguísticas sociais e cognitivas, já que a língua é uma atividade interativa, e o texto não é apenas um produto. Assim, a atenção deve estar nos processos de compreensão que se dão pelas atividades, habilidades e nos modos de produção de sentido.

Refletindo acerca dos OED intitulados Gráficos, Leitura de infográfico e Notícia (também referentes aos gêneros textuais e às práticas de leitura e escrita), é possível afirmar que esses objetos buscam propiciar o entendimento sobre a tipicidade de um gênero por meio de suas funções, propósitos e ações, mostrando ao usuário como eles se comportam em práticas comunicativas. Esses OED apresentam-se integrando alguns modos de linguagem, incluindo texto escrito, som e imagem (fixa e em movimento vídeo), atribuindo certo grau de importância à linguagem audiovisual concomitantemente à escrita. Assim, esses OED mostram-se de acordo com a pedagogia de multiletramentos de Rojo (2017), envolvendo atividades nas quais os usuários têm a chance de compreender o funcionamento dos gêneros em situações comunicativas autênticas cotidianas.

Apesar de todas essas considerações, ainda é importante destacar que os OED parecem ainda uma simples digitalização de um material impresso ou então uma simples passagem de um conteúdo que estava em um CD-Room para um OED. Acerca disso, Rojo (2017) afirma que a cultura do impresso que se refere aos livros e aos textos xerocados (presentes na escola desde o final do século $X I X$ e no século $X X$ ), que acompanhavam as práticas pedagógicas de cópias do livro e do quadro negro, o ditado, questões fechadas de avaliação, entre outras, ainda são práticas que permanecem nas escolas atuais, tendo como referência uma mentalidade escolar disciplinadora. Vejamos:

[...] eram e são práticas da escola da modernidade, em que o ensino visava disciplinar corpo, linguagem e mente (CHERVEL, 1990) e em que o texto, escrito ou impresso, convoca práticas letradas muito específicas, de confiança, respeito e repetição/reprodução; de reverência (ROJO, 2017, p. 7).

As práticas pedagógicas que, segundo a autora, visam disciplinar corpo, linguagem e mente podem ser observadas nos OED que analisamos nos tópicos anteriores, visto que se apresentam, principalmente em relação aos exercícios propostos, como atividades de reprodução e repetição em relação ao ensino de LP. Esse é um fato que evidencia que as tecnologias digitais e os novos multiletramentos da cultura digital não alcançaram efetivamente, até o momento, as atividades escolares, que continuam aferradas ao 
impresso e a suas práticas.

\section{Considerações finais}

Já se reconhece que os OED estão cada vez mais ganhando espaço nas coleções didáticas indicadas para o ensino fundamental e médio e, por isso, propôs-se, neste trabalho, uma análise desse material digital a fim de verificar se os mesmos podem contribuir para um ensino pluricultural e multissemiótico da língua materna.

No entanto, observou-se que a simples inclusão de OED em um livro didático não garante um ensino pautado em perspectivas contemporâneas, pois, em muitos casos, trazem atividades mecânicas que ignoram o possível potencial desse material digital.

Sendo assim, ao que nos foi possível analisar, esses objetos digitais educacionais referentes ao ensino de gramática e de gêneros textuais não se mostram, em sua grande maioria, em sua melhor estrutura para o ensino de Língua Portuguesa, tendo em vista que parecem desconsiderar os pressupostos teórico-metodológicos que devem acompanhar o desenvolvimento desse material digital, a fim de promover aprendizagens significativas. Além disso, pode-se levantar a hipótese de que os princípios estabelecidos por Leffa (2006) também não garantem que os OED sejam condizentes com metodologias apropriadas ao processo de ensino-aprendizagem, tendo em vista que todos os OED se encaixam em $75 \%$ dessas características não contendo apenas uma e, ainda assim, apresentam barreiras para o ensino de língua materna.

Em relação ao uso das práticas multiletradas nos OED expostos neste trabalho, percebe-se que os exercícios ofertados pelos objetos digitais ainda são compreendidos como sendo uma digitalização do material impresso, tendo em vista o modo como são apresentados aos usuários. Observando as imagens anteriores referentes aos objetos, encontramos exercícios puramente de múltipla escolha, os quais podem ser, e são ainda, tranquilamente utilizados em atividades e avaliações impressas. Por consequência, notase que a escola não incorporou centralmente essas novas linguagens em suas práticas e, por isso, a cultura do impresso ainda está presente nas práticas de ensino, ainda que essas estejam disponíveis por meio da tecnologia, como no caso dos OED.

Diante disso, em acordo com a afirmação acima, Leffa aponta que os objetos de aprendizagem se encontram, geralmente, em uma unidade maior na qual não são especificamente identificados e, por isso, apresentam-se estáticos. Dessa forma, os OAs não têm seu potencial explorado devido ao fato de parecerem apenas uma transcrição do material impresso.

A maior parte dos OAs ainda está anonimamente inserida em atividades mais amplas, sem qualquer identificação, o que torna quase impossível sua recuperação. Geralmente fazem parte de um conjunto maior - unidade de ensino, disciplina ou curso - e, embora sejam responsáveis pela aprendizagem que ocorre nessas unidades maiores, não são identificados individualmente, ocultando-se na designação geral do conjunto. Formam um bloco monolítico, estruturalmente engessado, como se estivessem publicados em papel, sem usufruir da fluidez característica do suporte eletrônico (LEFFA, 2006, p. 14-15). 
O autor também aponta que esses materiais despertam elogios, críticas e ainda costumam ser utilizados como manobra de marketing para a venda das coleções didáticas às escolas.

Com o objetivo de responder ao difícil questionamento apresentado, inicialmente, no subtítulo deste trabalho, propõe-se que os OED analisados podem ser considerados permanências para o ensino de língua materna, por estarem atrelados à cultura do material impresso. No entanto, devido ao que se espera de um OED, parece-nos também como certo retrocesso atribuir a um material tecnológico um caráter tão tradicional explorando em poucos momentos as utilidades dessa TDIC. Ainda assim, vale ressaltar que se tratando de um tema presente na atualidade que parece perdurar nas próximas décadas, entende-se neste trabalho que ainda que os OED analisados se mostrem, em sua maioria, insatisfatórios é preciso lembrar que eles são materiais novos no processo de ensino-aprendizagem e, por isso, é possível considerar que estão no caminho para se tornarem cada vez mais auxiliadores de aprendizagens significativas.

Por fim, vale destacar que esta pesquisa investigou o material que acompanha apenas uma coleção indicada para uso nos próximos três anos de ensino. Seria interessante, como proposta para futuros trabalhos, investigar os OED pertencentes aos demais manuais que entrarão em classe no território brasileiro no triênio 2018-2020 e também materiais de outras produtoras de coleções didáticas para se obter um panorama geral acerca da contribuição (ou não) dos OED para o ensino de língua materna na educação básica.

\section{Referências}

ANTUNES, I. Muito além da gramática: por um ensino de línguas sem pedras no caminho. São Paulo: Parábola Editorial, 2007.

BRASIL. Secretaria de Educação Fundamental. Orientações Educacionais Complementares aos Parâmetros Curriculares Nacionais do Ensino Médio. (PCNEM+) I Secretaria de Educação Fundamental. Brasília: MEC/SEF, 1997a.

BRASIL. Secretaria de Educação Fundamental. Parâmetros curriculares nacionais: introdução aos parâmetros curriculares nacionais/Secretaria de Educação Fundamental. Brasília: MEC/SEF, 1997b.

BRASIL. Guia de livros didáticos. PNLD 2014. Língua Portuguesa, ensino fundamental: anos finais. Brasília: Ministério da Educação, Secretaria de Educação Básica, 2013.

BRASIL. Ministério da Educação. Edital de Convocação para o Processo de Inscrição e Avaliação de Coleções Didáticas para o Programa Nacional do Livro Didático PNLD 2014. Brasília: MEC/FNDE/SEB, 2011. Disponível em < http://www.fnde.gov.br/programas/livrodidatico/livro-didatico-editais/item/3963-pnld-2014anos-finais-do-ensino-fundamental>. Acesso em: 10 out. 2017.

COLL, C.; MAURI, T.; ONRUBIA, J. A incorporação das tecnologias da informação e da 
comunicação na educação: do projeto técnico-pedagógico às práticas de uso. In: COLL, C.; MONEREO, C. Psicologia da Educação Virtual: aprender e ensinar com as tecnologias da informação e da comunicação. Porto Alegre: Artmed, 2010. p. 66-93.

COSCARELLI, C. V. Textos e hipertextos: procurando o equilíbrio. Linguagem em (Dis)curso, Santa Catarina, v. 9, n. 3, p. 549-564, set./dez. 2009. Disponível em: <http://www.scielo.br/pdf/ld/v9n3/06.pdf>. Acesso em: 12 nov. 2017.

DIONÍSIO, A. P. Gêneros textuais e multimodalidade. In: KARWOSKI, A., GAYDECKZA, B. \& BRITO, K. (Org.). Gêneros Textuais: reflexões e ensino. São Paulo: Parábola, 2011. p. $159-177$.

DIONÍSIO, A. P. Multimodalidades e leituras: funcionamento cognitivo, recursos semióticos, convenções visuais. Recife: Pipa Comunicação, 2014.

E.DOCENTE. Portal de apoio pedagógico. Disponível em: <http://edocente.plurall.net/>. Acesso em: 10 de novembro de 2017.

KEMIAC, L.; ARAÚJO, Denise L. de. Princípios subjacentes à literatura sobre análise linguística. Revista Leia Escola, Campina Grande, v. 10. n. 1, p. 45-58, 2010.

LALUEZA, J. L.; CRESPO, Isabel; CAMPS, S. As tecnologias da informação e da comunicação e os processos de desenvolvimento e socialização. In: COLL, C.; MONEREO, C. Psicologia da Educação Virtual: aprender e ensinar com as tecnologias da informação e da comunicação. Porto Alegre: Artmed, 2010. p. 47-67.

LEFFA, V. J. Nem tudo que balança cai: Objetos de aprendizagem no ensino de línguas. Polifonia. Cuiabá, v. 12, n. 2, p. 15-45, 2006.

MARCUSCHI, L. A. Produção textual, análise de gêneros e compreensão. São Paulo: Parábola Editorial, 2008.

ROJO, R. Pedagogia dos Multiletramentos: Diversidade cultural e de linguagens na escola. In: ROJO, R. H. R.; MOURA, E. (Org.). Multiletramentos na Escola. SP: Parábola, 2012. p. 11-32.

ROJO, R. Gêneros discursivos do Círculo de Bakhtin e multiletramentos. In: ROJO, R. (Org.). Escol@ conectada: os multiletramentos e as TICs. São Paulo: Parábola Editorial, 2013, p. 13-36.

ROJO, R. Entre plataformas, ODAs e protótipos: novos multiletramentos em tempos de web2. The especialist: Ensino e Aprendizagem, v. 38, n. 1, p. 01-20, jan-jul. 2017.

WILEY, D. A. Connecting learning objects to instructional design theory: a definition, a metaphor, and a taxonomy, In: WILEY, D. A. (Ed.). The instructional use of learning objects 2000. p. 01-35. Disponível em: <http://www.reusability.org/read/chapters/wiley.doc>. Acesso em: 26 out. 2017. 
WILEY, D. A. The instructional use of learning objects. 2002. Disponível em: $<$ http://www.reusability.org/read/>. Acesso em: 10 nov. 2017.

Recebido em dia 27 de julho de 2018. Aprovado em dia 30 de agosto de 2018. 